\title{
Intercomparison of meteorological analyses and trajectories in the Antarctic lower stratosphere with Concordiasi superpressure balloon observations
}

\author{
Lars Hoffmann ${ }^{1}$, Albert Hertzog ${ }^{2}$, Thomas Rößler ${ }^{1}$, Olaf Stein ${ }^{1}$, and Xue Wu ${ }^{1,3}$ \\ ${ }^{1}$ Jülich Supercomputing Centre, Forschungszentrum Jülich, Jülich, Germany \\ ${ }^{2}$ Laboratoire de Météorologie Dynamique, École Polytechnique, IPSL, Palaiseau, France \\ ${ }^{3}$ Institute of Atmospheric Physics, Chinese Academy of Sciences, Beijing, China \\ Correspondence to: Lars Hoffmann (1.hoffmann@fz-juelich.de)
}

Received: 26 January 2017 - Discussion started: 17 February 2017

Revised: 29 May 2017 - Accepted: 7 June 2017 - Published: 4 July 2017

\begin{abstract}
In this study we compared temperatures and horizontal winds of meteorological analyses in the Antarctic lower stratosphere, a region of the atmosphere that is of major interest regarding chemistry and dynamics of the polar vortex. The study covers the European Centre for MediumRange Weather Forecasts (ECMWF) operational analysis, the ERA-Interim reanalysis, the Modern-Era Retrospective analysis for Research and Applications version 1 and 2 (MERRA and MERRA-2), and the National Centers for Environmental Prediction and National Center for Atmospheric Research (NCEP/NCAR) reanalysis. The comparison was performed with respect to long-duration observations from 19 superpressure balloon flights during the Concordiasi field campaign in September 2010 to January 2011. Most of the balloon measurements were conducted at altitudes of $17-$ $18.5 \mathrm{~km}$ and latitudes of $60-85^{\circ} \mathrm{S}$. We found that large-scale state temperatures of the analyses have a mean precision of $0.5-1.4 \mathrm{~K}$ and a warm bias of $0.4-2.1 \mathrm{~K}$ with respect to the balloon data. Zonal and meridional winds have a mean precision of $0.9-2.3 \mathrm{~m} \mathrm{~s}^{-1}$ and a bias below $\pm 0.5 \mathrm{~m} \mathrm{~s}^{-1}$. Standard deviations related to small-scale fluctuations due to gravity waves are reproduced at levels of $15-60 \%$ for temperature and $30-60 \%$ for the horizontal winds. Considering the fact that the balloon observations have been assimilated into all analyses, except for NCEP/NCAR, notable differences found here indicate that other observations, the forecast models, and the data assimilation procedures have a significant impact on the analyses as well. We also used the balloon observations to evaluate trajectory calculations with our new Lagrangian transport model Massive-Parallel Trajectory Calcu-
\end{abstract}

lations (MPTRAC), where vertical motions of simulated trajectories were nudged to pressure measurements of the balloons. We found relative horizontal transport deviations of $4-12 \%$ and error growth rates of $60-170 \mathrm{~km} \mathrm{day}^{-1}$ for $15-$ day trajectories. Dispersion simulations revealed some difficulties with the representation of subgrid-scale wind fluctuations in MPTRAC, as the spread of air parcels simulated with different analyses was not consistent. However, although case studies suggest that the accuracy of trajectory calculations is influenced by meteorological complexity, diffusion generally does not contribute significantly to transport deviations in our analysis. Overall, evaluation results are satisfactory and compare well to earlier studies using superpressure balloon observations.

\section{Introduction}

The seasonal formation and decay of the Southern Hemisphere polar vortex is likely the most prominent feature of the extratropical stratospheric circulation (e.g., Schoeberl and Hartmann, 1991; Newman and Schoeberl, 2003; Waugh and Polvani, 2010). The structure and dynamics of the polar vortex play a key role in the winter and spring stratospheric circulation and coupling between the stratosphere and troposphere. A number of studies have demonstrated that the polar vortex can influence tropospheric weather and climate (Baldwin and Dunkerton, 1999; Polvani and Kushner, 2002; Thompson et al., 2002; Baldwin et al., 2003). Furthermore, the polar vortex acts as a cold trap for stratospheric air, which 
plays a critical role in polar ozone depletion and the annual formation of the Antarctic ozone hole (Solomon, 1999, and references therein). These topics have motivated various observational and modeling studies in recent years to better understand the structure and dynamics of the polar vortex as well as implications on polar ozone loss in the stratosphere. Among those, a number of studies focused on the evaluation of the representation of the Southern Hemisphere polar vortex in meteorological reanalyses (Manney et al., 1996, 2005; Lawrence et al., 2015).

Lagrangian particle dispersion models are indispensable tools to study atmospheric transport processes (e.g., Lin et al., 2012). Trajectory calculations in Lagrangian transport simulations are commonly driven by wind fields from global meteorological reanalyses. The accuracy of trajectory calculations depends on various factors, including interpolation and sampling errors related to the finite spatial resolution of the meteorological data as well as errors of the wind field itself, which are introduced during the data assimilation process (e.g., Stohl, 1998; Bowman et al., 2013). In this study we conducted an intercomparison of temperature and wind data as well as trajectory calculations for the Antarctic lower stratosphere using different meteorological data sets. We considered four reanalyses, including the European Centre for Medium-Range Weather Forecasts (ECMWF) ERAInterim reanalysis (Dee et al., 2011), the Modern-Era Retrospective analysis for Research and Applications version 1 and 2 (MERRA and MERRA-2) reanalysis (Rienecker et al., 2011; Bosilovich et al., 2015), and the National Centers for Environmental Prediction and the National Center for Atmospheric Research (NCEP/NCAR) reanalysis (Kalnay et al., 1996). Furthermore, we compared with the ECMWF operational analysis (OA), which is produced with significantly higher spatial resolution. The analyses data are compared with superpressure balloon observations during the Concordiasi field campaign (Rabier et al., 2010) in September 2010 to January 2011. During the campaign 19 superpressure balloons were launched from McMurdo Station $\left(78^{\circ} \mathrm{S}, 166^{\circ} \mathrm{E}\right)$, Antarctica. Each balloon flew in the mid- and high-latitude lower stratosphere for a typical period of 3 months. The sensors aboard the balloons provide position, pressure, and temperature at high accuracy and high temporal sampling. Various studies demonstrated that superpressure balloon observations constitute an excellent source of data for the evaluation of meteorological analyses (Knudsen et al., 1996, 2002; Hertzog et al., 2004, 2006; Knudsen et al., 2006; Boccara et al., 2008; Podglajen et al., 2014; Friedrich et al., 2017).

Here we applied the Lagrangian particle dispersion model Massive-Parallel Trajectory Calculations (MPTRAC) (Hoffmann et al., 2016) to conduct the trajectory calculations for the balloon observations. MPTRAC is a rather new model and our study mainly serves the purpose of evaluating this model. However, the methods and results are also transferable to other Lagrangian models for the stratosphere, e.g., the Chemical Lagrangian Model of the Stratosphere (CLaMS)
(McKenna et al., 2002a, b) or the Alfred Wegener Institute Lagrangian Chemistry/Transport System (ATLAS) (Wohltmann and Rex, 2009). The results of the trajectory evaluation are of particular interest for studies applying the "Match" technique (von der Gathen et al., 1995; Rex et al., 1997) to assess polar ozone loss. In order to distinguish between chemically and transport-induced changes of ozone abundance, the Match approach uses trajectory calculations to relate ozone observations within the same air mass at different locations to each other. The results of the intercomparison of the temperature and wind data of the meteorological analyses may be of interest for studies using chemistry-transport models to assess polar ozone loss in the stratosphere (e.g., Chipperfield, 1999; Grooß et al., 2002, 2005; Wohltmann et al., 2013). Our new study also contributes to current research activities that focus on intercomparisons of different reanalyses, including the Stratosphere-troposphere Processes And their Role in Climate (SPARC) Reanalysis Intercomparison Project (S-RIP) (Fujiwara et al., 2017).

In Sect. 2 we introduce the superpressure balloon observations during the Concordiasi campaign. We also describe the five meteorological data sets and discuss the meteorological conditions during the campaign. Furthermore, we introduce the Lagrangian particle dispersion model MPTRAC and the approach used for trajectory evaluation. The results of our study are provided in Sect. 3. In the first part we compare temperatures and horizontal winds of the different meteorological data sets directly at the position of the balloon measurements. In the second part we focus on the evaluation of trajectory calculations, where we assess different types of vertical motions, the impact of the different meteorological data sets, and the impact of subgrid-scale wind fluctuations. Finally, Sect. 4 provides a summary and conclusions.

\section{Data and methods}

\subsection{Superpressure balloon observations}

Superpressure balloons are aerostatic balloons, which are filled with a fixed amount of lifting gas, and for which the maximum volume of the balloon is kept constant by means of a closed, inextensible, spherical envelope. After launch, the balloons ascend and expand until they reach a float level where the atmospheric density matches the balloon density. On this isopycnic surface a balloon is free to float horizontally with the motion of the wind. Hence, superpressure balloons behave as quasi-Lagrangian tracers in the atmosphere. In this study we analyzed superpressure balloon observations in the lower stratosphere during the Concordiasi field campaign in Antarctica in September 2010 to January 2011. The Concordiasi field campaign aimed at making innovative atmospheric observations to study the circulation and chemical species in the polar lower stratosphere and to reduce uncertainties in diverse fields in Antarctic science (Rabier et al., 
Table 1. Concordiasi balloon flights over Antarctica in September 2010 to January 2011.

\begin{tabular}{lllll}
\hline Flight number & Flight code & Gondola ID & Flight start & Flight end \\
\hline 1 & MSD01 & 10V01N46 & $2010 / 09 / 23$ & $2010 / 12 / 11$ \\
2 & MSD02 & 10V02N48 & $2010 / 09 / 23$ & $2010 / 11 / 18$ \\
3 & MSD03 & 10V03N39 & $2010 / 10 / 15$ & $2010 / 11 / 04$ \\
4 & MSD04 & 10V04N40 & $2010 / 09 / 24$ & $2010 / 12 / 27$ \\
5 & MSD05 & 10V05N44 & $2010 / 09 / 25$ & $2010 / 12 / 22$ \\
6 & MSD06 & 10V06N37 & $2010 / 09 / 28$ & $2010 / 12 / 09$ \\
7 & MSD07 & 10V07N41 & $2010 / 09 / 30$ & $2010 / 12 / 09$ \\
8 & MSD08 & 10V08N49 & $2010 / 10 / 26$ & $2011 / 01 / 19$ \\
9 & MSD09 & 10V09N22 & $2010 / 10 / 07$ & $2011 / 01 / 04$ \\
10 & MSD10 & 10V10N25 & $2010 / 10 / 14$ & $2010 / 12 / 24$ \\
11 & MSD11 & 10V11N56 & $2010 / 10 / 19$ & $2010 / 12 / 29$ \\
12 & MSD12 & 10V12N66 & $2010 / 10 / 20$ & $2011 / 01 / 23$ \\
13 & MSD13 & 10V13N65 & $2010 / 10 / 19$ & $2010 / 11 / 30$ \\
14 & PSC14 & 10V14N42 & $2010 / 09 / 15$ & $2010 / 12 / 21$ \\
15 & PSC15 & 10V15N32 & $2010 / 09 / 08$ & $2010 / 09 / 16$ \\
16 & PSC16 & 10V16N35 & $2010 / 09 / 11$ & $2010 / 10 / 11$ \\
17 & PSC17 & 10V17N31 & $2010 / 09 / 14$ & $2010 / 12 / 10$ \\
18 & PSC18 & 10V18N43 & $2010 / 09 / 29$ & $2010 / 12 / 16$ \\
19 & PSC19 & 10V19N27 & $2010 / 10 / 08$ & $2010 / 12 / 24$ \\
\hline
\end{tabular}

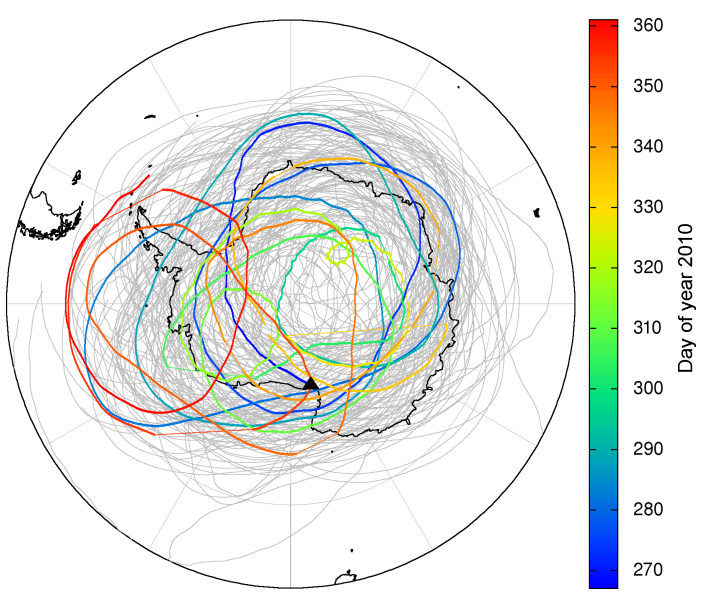

Figure 1. Map of superpressure balloon trajectories (gray curves) during the Concordiasi field campaign in Antarctica in September 2010 to January 2011. The colored curve highlights the trajectory of flight number 4 . The black triangle shows the location of McMurdo Station.

2010). During the field campaign 19 superpressure balloons with $12 \mathrm{~m}$ diameter were launched from McMurdo Station $\left(78^{\circ} \mathrm{S}, 166^{\circ} \mathrm{E}\right)$, Antarctica, by the French space agency, Centre National d'Etudes Spatiales (CNES). Balloons of this size typically drift at pressure levels of $\sim 60 \mathrm{hPa}$ and altitudes of $\sim 18 \mathrm{~km}$. The balloons were launched between 8 September and 26 October 2010, and each balloon flew in the midand high-latitude lower stratosphere for a typical period of 2 to 3 months. The flight dates are summarized in Table 1 and the balloon trajectories are shown in Fig. 1.
The positions of the balloons were tracked every $60 \mathrm{~s}$ by means of global positioning satellite (GPS) receivers. At each observation time the components of the horizontal wind are computed by finite differences between the GPS positions. The uncertainty is about $1 \mathrm{~m}$ for the GPS horizontal position and $0.1 \mathrm{~m} \mathrm{~s}^{-1}$ for the derived winds (Podglajen et al., 2014). Each balloon launched during Concordiasi was equipped with a meteorological payload called the Thermodynamical SENsor (TSEN). TSEN makes in situ measurements of atmospheric pressure and temperature every $30 \mathrm{~s}$ during the whole flight. The pressure is measured with an accuracy of $1 \mathrm{~Pa}$ and a precision of $0.1 \mathrm{~Pa}$. The air temperature is measured via two thermistors. During daytime, the thermistors are heated by the sun, leading to daytime temperature measurements being warmer than the real air temperature. An empirical correction has been used to correct for this effect, which is described in detail by Hertzog et al. (2004). The precision of the corrected temperature observations is $\sim 0.25 \mathrm{~K}$ during daytime and $\sim 0.1 \mathrm{~K}$ during nighttime. Note that technical issues aboard the scientific gondola caused a few data gaps in the TSEN data set, but most of them were shorter than $15 \mathrm{~min}$.

In order to quantify the coverage of the balloon observations during the free-flying phases, we independently calculated the 5 and $95 \%$ quantiles of various parameter distributions. All statistics presented in this paper are most representative for the parameter ranges reported below. Any findings for parameters outside these ranges need to be considered carefully, because only a few measurements are available to support them. We found that most of the measurements (i.e., more than $90 \%$ ) took place between 25 September and 

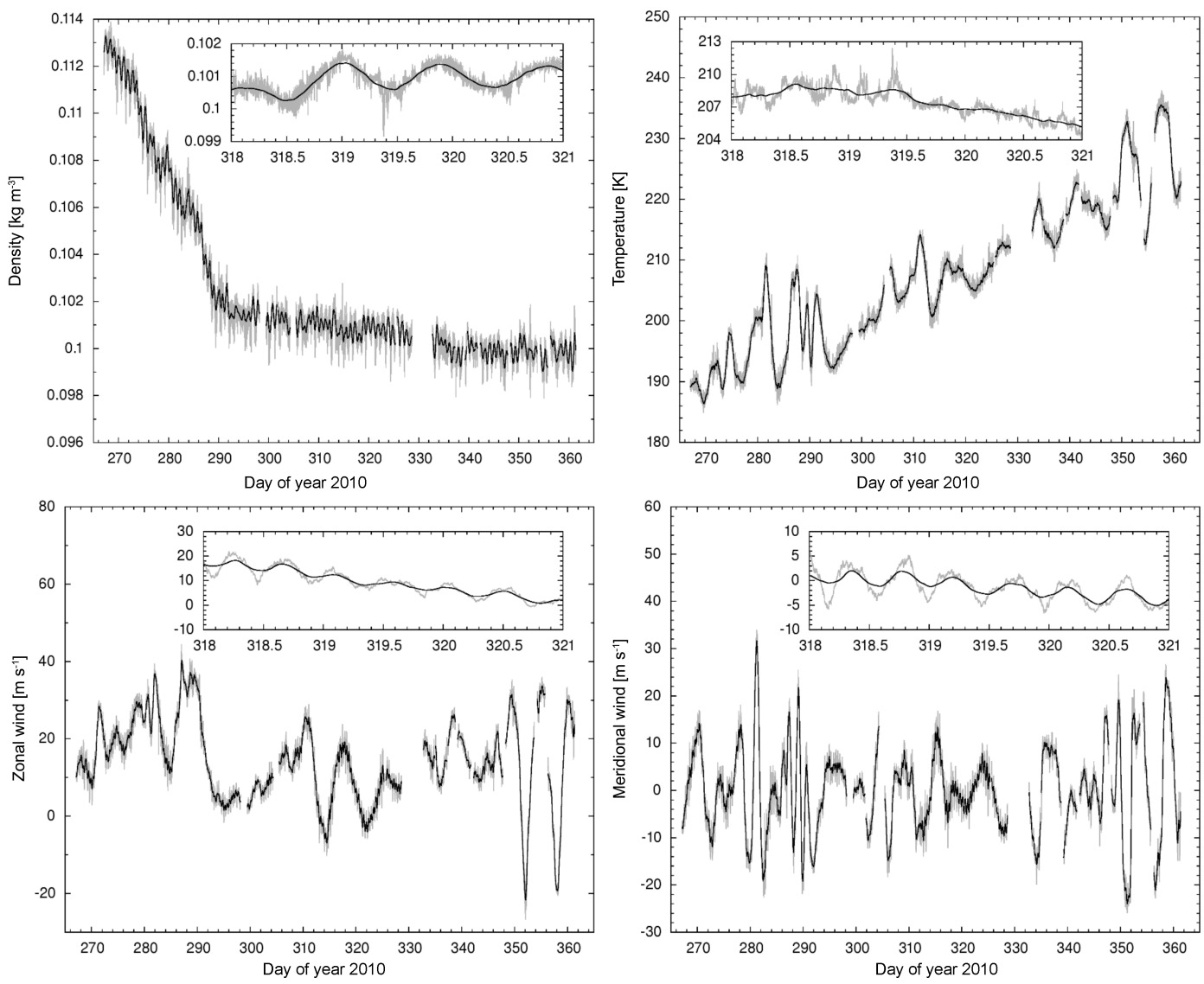

Figure 2. Time series of meteorological data of flight number 4 of the Concordiasi campaign (see Fig. 1). Gray curves show unfiltered data from GPS and TSEN measurements at $30 \mathrm{~s}$ time intervals. Black curves show results of a low-pass filter with $15 \mathrm{~h}$ cut-off frequency. Inset plots show data for 14-17 November 2010.

22 December 2010, at an altitude range of $17.0-18.5 \mathrm{~km}$, and within a latitude range of $59-84^{\circ} \mathrm{S}$. The pressure measurements are mostly within a range of $58.2-69.1 \mathrm{hPa}$ and the temperature measurements within $189-227 \mathrm{~K}$. The density of air, calculated from pressure and temperature, varies between 0.099 and $0.120 \mathrm{~kg} \mathrm{~m}^{-3}$. The zonal winds are predominately westerly and mostly within a range of $1-44 \mathrm{~m} \mathrm{~s}^{-1}$. The meridional wind distributions are nearly symmetric, with meridional winds being in the range of $\pm 17 \mathrm{~m} \mathrm{~s}^{-1}$. Horizontal wind speeds are mostly within $5-47 \mathrm{~m} \mathrm{~s}^{-1}$.

As an example, Fig. 2 shows time series of density, temperature, zonal wind, and meridional wind as measured during flight number 4 of the Concordiasi campaign. The density time series shows decreasing density during the first 20 days, but remains rather stable thereafter. This initial decrease in density is due to the release of dropsondes, which are another part of the balloon payloads on flight number 1-13. The release of dropsondes changes the overall mass configuration of the balloon-gondola system, which is compensated by changes in density. A closer inspection of the time series also reveals diurnal variations in the balloon density. During the day the balloon envelope is heated by the sun, which increases the temperature and pressure of the gas inside the balloon. The balloon slightly expands in return, which decreases its equilibrium density. In addition to this regular daily pattern, the time series show notable variability on even shorter timescales, including semi-diurnal oscillations of the horizontal winds, which are attributed to near-inertial gravity waves and semi-diurnal tides. As we do not expect the reanalyses to reproduce those fluctuations with great accuracy, we applied a band-pass filter with $15 \mathrm{~h}$ cut-off period to separate between small-scale features (e.g., pure and inertia-gravity waves) and the large-scale state (e.g., zonal temperature gradients and planetary waves). The cut-off period of the bandpass filter was selected to cover the longest inertial periods in the balloon data set, $T=2 \pi f^{-1}$, with Coriolis parameter $f$, ranging from about $12.0 \mathrm{~h}$ at $85^{\circ} \mathrm{S}$ to $13.9 \mathrm{~h}$ at $60^{\circ} \mathrm{S}$. Figure 2 illustrates the effect of low-pass filtering to extract the large-scale state.

\subsection{Meteorological data}

In this study we considered five meteorological data sets, the ECMWF operational analysis, ERA-Interim (Dee 
Table 2. Temporal and spatial resolution of meteorological data sets as considered in this study

\begin{tabular}{lllll}
\hline Data product & $\begin{array}{l}\text { Temporal } \\
\text { resolution }\end{array}$ & $\begin{array}{l}\text { Top } \\
\text { level }\end{array}$ & $\begin{array}{l}\text { Vertical } \\
\text { levels }\end{array}$ & $\begin{array}{l}\text { Horizontal } \\
\text { resolution }\end{array}$ \\
\hline ECMWF OA & $3 \mathrm{~h}$ & $0.01 \mathrm{hPa}$ & 91 & $0.125^{\circ} \times 0.125^{\circ}$ \\
ERA-Interim & $6 \mathrm{~h}$ & $0.1 \mathrm{hPa}$ & 60 & $1.000^{\circ} \times 1.000^{\circ}$ \\
MERRA-2 & $3 \mathrm{~h}$ & $0.01 \mathrm{hPa}$ & 72 & $0.500^{\circ} \times 0.667^{\circ}$ \\
MERRA & $3 \mathrm{~h}$ & $0.1 \mathrm{hPa}$ & 42 & $1.250^{\circ} \times 1.250^{\circ}$ \\
NCEP/NCAR & $6 \mathrm{~h}$ & $10 \mathrm{hPa}$ & 17 & $2.500^{\circ} \times 2.500^{\circ}$ \\
\hline
\end{tabular}

et al., 2011), MERRA (Rienecker et al., 2011), MERRA-2 (Bosilovich et al., 2015), and the NCEP/NCAR reanalysis (Kalnay et al., 1996). Fujiwara et al. (2017) provides a review of key aspects of the reanalyses. Table 2 summarizes information on spatial and temporal resolution and coverage of the data sets as considered in this study. Note that the five data sets vary substantially in resolution, i.e., by a factor of 2 in temporal resolution, by a factor of 5 in vertical resolution, and by a factor of $20 \times 20$ in horizontal resolution. We retrieved the data sets at the temporal and spatial resolution at which they are typically provided to the users by the respective centers. Following Hoffmann et al. (2016), both ECMWF data sets were retrieved on hybrid sigma-pressure levels and converted to pressure levels by means of the Climate Data Operators (Schulzweida, 2014), whereas MERRA and NCEP/NCAR data were retrieved directly on pressure levels. For MERRA-2 we implemented new code in our Lagrangian transport model in order to be able to process meteorological data directly on hybrid sigma-pressure levels, which finally allowed us to consider MERRA-2 data with higher spatial resolution in this study.

An important aspect that needs to be taken into account in a comparison of the Concordiasi balloon observations and the meteorological data sets is that the balloon observations have been subject to data assimilation. In particular, $15 \mathrm{~min}$ time averaged data from the Concordiasi balloons have been transmitted over the Global Telecommunication System (GTS) (Rabier et al., 2013). The data transmitted over GTS were then assimilated by the respective centers. The Concordiasi balloon observations have been assimilated into the ECMWF data sets, MERRA, and MERRA2 , but they were not considered for the NCEP/NCAR reanalysis. The observations therefore provide an independent data source for validation only for the NCEP/NCAR data set. However, as meteorological analyses are a result of combining various satellite and in situ observations, a forecast model, and a data assimilation procedure, a comparison of the meteorological data with the Concordiasi observations still provides information on the performance of the overall system. As the observational data have been subject to downsampling and data thinning before they were assimilated, an assessment of the representation of small-scale structures due to gravity waves also remains meaningful.

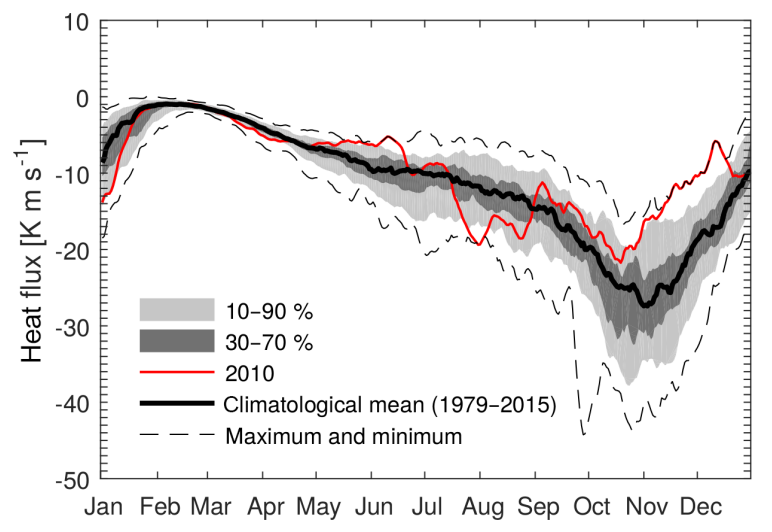

Figure 3. Activity of the polar vortex at $50 \mathrm{hPa}$ as represented by the 45-day running mean of the eddy heat flux between 45 and $75^{\circ} \mathrm{S}$. The red curve shows results for the year 2010. Black and gray curves illustrate statistics of the long-term mean (1979-2015). This analysis was obtained from NASA Ozone Watch from their web site at https://ozonewatch.gsfc.nasa.gov (last access: 16 December 2016) and is based on MERRA-2 data.

The Concordiasi balloon measurements cover the final stratospheric warming and decay of the Southern Hemisphere polar vortex during 2010/2011 austral spring to summer. Although a mid-winter minor sudden stratospheric warming during July and early August 2010 resulted in an off-pole displacement and weakening of the stratospheric polar vortex (De Laat and van Weele, 2011; Klekociuk et al., 2011), the polar vortex returned to be relatively stable from mid-August to October, except for a second short warming that began in early September. This pattern was primarily attributed to the quasi-biennial oscillation being in a strong westerly or positive phase that helped to maintain a persistent polar vortex. According to NASA Ozone Watch and the World Meteorological Organization Antarctic Ozone Bulletins (see http://www.wmo.int/pages/prog/arep/gaw/ozone/ index.html; last access: 30 September 2016), the longitudinally averaged poleward eddy heat flux between 45 and $75^{\circ} \mathrm{S}$, which is an indicator of disturbance in polar stratosphere, was much smaller than the long-term mean (Fig. 3), indicating that the vortex was relatively unperturbed from mid-September to December. 
Figure 4 illustrates that the polar vortex was typically quite symmetric and stable in September and October. Afterwards, the polar vortex elongated and weakened gradually through November, was displaced off the pole in mid-December and broke down by mid-January 2011. The vortex breakup was marked when the winds around the vortex edge decreased below $15 \mathrm{~m} \mathrm{~s}^{-1}$ on the $475 \mathrm{~K}$ potential temperature surface. From an analysis of temperatures on the levels where most of the balloon measurements were attained (about 50-60 hPa, $\sim 475 \mathrm{~K}$ ), the final warming started from mid-October with development of strong zonal asymmetries in temperature. The cold pool over the South Pole declined and displaced, and until the end of November, minimum temperatures over Antarctica increased from around 180 to $220 \mathrm{~K}$. A warm pool with temperatures of 230-240 K dominated Antarctica from end of December. Consistent with the warming process, the polar jet showed a pronounced reduction in wind speed from $70 \mathrm{~m} \mathrm{~s}^{-1}$ at the beginning of September to $40 \mathrm{~m} \mathrm{~s}^{-1}$ by mid of December and then further weakened to less than $20 \mathrm{~m} \mathrm{~s}^{-1}$ from beginning of January.

\subsection{Trajectory calculations}

We conducted the trajectory calculations for the Concordiasi balloon observations with the Lagrangian particle dispersion model MPTRAC (Hoffmann et al., 2016). MPTRAC has been developed to support analyses of atmospheric transport processes in the free troposphere and stratosphere. In previous studies it was used to perform transport simulations for volcanic eruptions and to reconstruct time- and heightresolved emission rates for these events (Heng et al., 2016; Hoffmann et al., 2016). Transport is simulated by calculating trajectories for large numbers of air parcels based on given wind fields from global meteorological reanalyses. The numerical accuracy and efficiency of trajectory calculations with MPTRAC was assessed by Rößler et al. (2017). Turbulent diffusion and subgrid-scale wind fluctuations are simulated based on the Langevin equation, closely following the approach implemented in the Flexible Particle (FLEXPART) model (Stohl et al., 2005). Additional modules allow us to simulate sedimentation and the decay of particle mass, but they were not used here. The model is particularly suited for large-scale simulations on supercomputers due to its efficient Message Passing Interface (MPI)/Open MultiProcessing (OpenMP) hybrid parallelization (Heng et al., 2016; Rößler et al., 2017).

Trajectory calculations are based on numerical integration of the kinematic equation of motion,

$$
\frac{\mathrm{d} \boldsymbol{x}}{\mathrm{d} t}=\boldsymbol{v}(\boldsymbol{x}, t),
$$

where $\boldsymbol{x}$ denotes the position and $\boldsymbol{v}$ the velocity of an air parcel at time $t$. The air parcel position $\boldsymbol{x}$ is defined by geographic latitude $\phi$ and longitude $\lambda$ as horizontal coordinates as well as pressure $p$ as vertical coordinate. The horizontal wind $(u, v)$ and vertical velocity $(\omega=\mathrm{d} p / \mathrm{d} t)$ at position $\boldsymbol{x}$ and time $t$ are obtained by 4-D linear interpolation of the meteorological data in space and time. The kinematic equation of motion is solved with the explicit midpoint method,

$\boldsymbol{x}(t+\Delta t)=$

$\boldsymbol{x}(t)+\boldsymbol{v}\left(\boldsymbol{x}(t)+\frac{\Delta t}{2} \boldsymbol{v}(\boldsymbol{x}(t), t), t+\frac{\Delta t}{2}\right) \Delta t$.

The time step $\Delta t$ mainly controls the trade-off between accuracy and speed of the calculations. For our simulations we selected $\Delta t=30 \mathrm{~s}$, which is sufficiently small so that truncation errors can be neglected (Rößler et al., 2017). This time step is also consistent with the sampling rate of the balloon data.

The diffusion module of MPTRAC considers two processes. Turbulent diffusion is modeled by means of uncorrelated, Gaussian random displacements of the air parcels with zero mean and standard deviations $\sqrt{D_{x} \Delta t}$ and $\sqrt{D_{z} \Delta t}$, where $D_{x}$ and $D_{z}$ are the horizontal and vertical diffusion coefficients, respectively. Typical values for the stratosphere are $D_{x}=0$ and $D_{z}=0.1 \mathrm{~m}^{2} \mathrm{~s}^{-1}$, according to choices made for the FLEXPART model (Legras et al., 2003; Stohl et al., 2005). Unresolved subgrid-scale wind fluctuations are most relevant for long-range simulations. These fluctuations are correlated over time and simulated with a Markov model, following the approach of Maryon (1998) and Stohl et al. (2005). For example, the zonal wind fluctuations $u^{\prime}$ of each air parcel are calculated according to

$u^{\prime}(t+\Delta t)=r u^{\prime}(t)+\sqrt{\left(1-r^{2}\right) \alpha \sigma_{u}^{2}} \xi$,

with $r=\exp \left(-2 \Delta t / \Delta t_{\text {met }}\right)$ being a correlation coefficient depending on the model time step $\Delta t$ and the time interval $\Delta t_{\text {met }}$ of the meteorological data (3 or $6 \mathrm{~h}$ ), $\alpha$ being a scaling factor used for downscaling of space and time grid-scale variances $\sigma_{u}^{2}$ to subgrid scales, and $\xi$ being a Gaussian random variate with zero mean and unity variance. The FLEXPART model uses a default value of $\alpha=0.16$ for downscaling of the grid-scale variances (or $40 \%$ in terms of standard deviations). Meridional wind and vertical velocity fluctuations are calculated in the same way.

For this study we implemented a new module in MPTRAC that allows us to simulate the vertical motions of the balloons more realistically. This module is called at each time step and adjusts the pressure of the air parcels so that vertical motions are constrained to either (i) an isobaric surface (constant pressure), (ii) an isopycnic surface (constant density), (iii) an isentropic surface (constant potential temperature), or (iv) the pressure time series measured by the balloon. In a first approximation the balloons move on isopycnic surfaces, which is represented by option (ii). However, the real dynamics of the balloons are more complex, in particular if they encounter small-scale structures such as gravity waves (Vincent and Hertzog, 2014). On longer timescales it needs to be considered that there are diurnal variations in the balloon density 

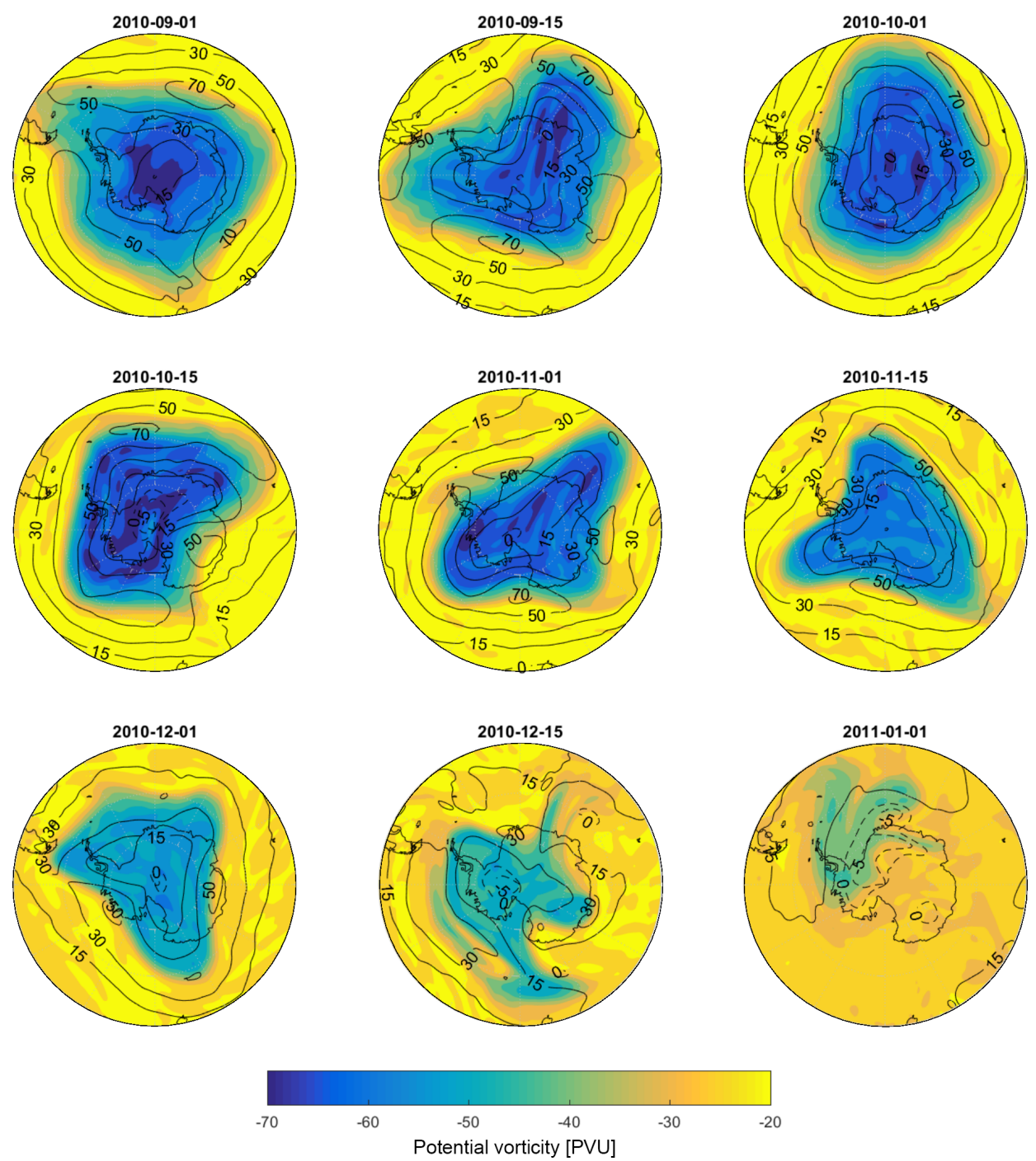

Figure 4. ERA-Interim potential vorticity $\left(1 \mathrm{PVU}=10^{-6} \mathrm{~K} \mathrm{~m}^{2} \mathrm{~s}^{-1} \mathrm{~kg}^{-1}\right.$; shaded) and zonal wind contours (m s $\mathrm{s}^{-1}$; black curves) on the $475 \mathrm{~K}$ isentropic surface. Data are shown for 00:00 UTC on selected days. Outer circles of the polar maps indicate a latitude of $45^{\circ} \mathrm{S}$. The prime meridian is oriented towards the top of the maps.

as well as overall mass variations due to the release of dropsondes (Sect. 2.1). These issues are partly circumvented by constraining the vertical motions to the balloon pressure data, which is represented by option (iv).

\subsection{Evaluation approach}

Although some of the Concordiasi balloon flights can be used to evaluate trajectory calculations for time periods as long as 3 months, we focused on shorter time windows. By splitting the balloon flights into smaller subsets of data, each containing 15 days of observations, we significantly increased the number of samples and improved the statistical accuracy of the results. To further increase the number of samples we also allowed for overlap of the time windows - i.e., we shifted the 15-day windows in steps of 5 days. A shift of 5 days between the windows was selected, because trajectory errors are usually larger than the effective resolution of the meteorological data sets after that time. This means we can consider the results of overlapping windows as being statistically independent. We varied the starting days for the analysis of the different flights to homogenize temporal coverage. As there are data gaps in the GPS and TSEN data of the balloon measurements, we imposed the requirement that each sample should have at least $90 \%$ coverage. Based on these criteria we obtained a set of 104 samples of 15-day time windows from the 19 Concordiasi balloon flights.

Absolute horizontal transport deviations (AHTDs) and relative horizontal transport deviations (RHTDs) are standard measures to compare trajectory calculations with observations or to evaluate results for different model configurations 
(Kuo et al., 1985; Rolph and Draxler, 1990; Stohl et al., 1995; Stohl, 1998). While other measures of trajectory error have also been defined, AHTDs and RHTDs are most often reported because they can be compared easily to other studies. The AHTD at travel time $t$ of the trajectories is calculated as

$$
\begin{aligned}
& \operatorname{AHTD}(t)= \\
& \frac{1}{N_{\mathrm{s}} N_{\mathrm{e}}} \sum_{i=1}^{N_{\mathrm{S}}} \sum_{j=1}^{N_{\mathrm{e}}} \sqrt{\left[X_{i, j}(t)-x_{i}(t)\right]^{2}+\left[Y_{i, j}(t)-y_{i}(t)\right]^{2}},
\end{aligned}
$$

where $N_{\mathrm{s}}$ refers to the number of reference trajectories and $N_{\mathrm{e}}$ refers to the size of the ensemble of test trajectories that is to be evaluated for each reference trajectory. The coordinates $\left(X_{i, j}, Y_{i, j}\right)$ and $\left(x_{i}, y_{i}\right)$ with $i=1, \ldots, N_{\mathrm{s}}$ and $j=1, \ldots, N_{\mathrm{e}}$ refer to the horizontal positions of the test and reference trajectories, respectively. Equation (4) is applied in different ways in this study. For instance, it is used to evaluate transport deviations between a model trajectory and a balloon trajectory for just one sample $\left(N_{\mathrm{s}}=1\right.$ and $\left.N_{\mathrm{e}}=1\right)$, between model and balloon trajectories for all samples $\left(N_{\mathrm{s}}=104\right.$ and $\left.N_{\mathrm{e}}=1\right)$, or for dispersion simulations $\left(N_{\mathrm{s}}=104\right.$ and $N_{\mathrm{e}}=1000$ ). Note that we calculated horizontal distances as Euclidean distances of the air parcel positions projected to the Earth's surface. RHTDs are calculated by dividing the AHTD of individual air parcels by the length of the corresponding reference trajectory. Absolute and relative vertical transport deviations (AVTDs and RVTDs) are defined similarly, based on pressure differences converted into vertical distances by means of the barometric formula.

\section{Results}

\subsection{Direct intercomparison of meteorological data}

In this section we focus on an intercomparison of temperatures and horizontal winds directly at the positions of the Concordiasi balloons. For this analysis the meteorological data are interpolated to the balloon positions by means of a 4-D linear interpolation in space and time. This interpolation scheme is most commonly applied in state-of-the-art Lagrangian transport models (Bowman et al., 2013). Table 3 presents summary statistics of low-pass-filtered meteorological data minus low-pass-filtered Concordiasi balloon observations, which indicates differences in the large-scale state (see Sect. 2.1). Table 3 shows that the analyses have a positive temperature bias in the range of 0.4 to $2.1 \mathrm{~K}$. Zonal wind biases are in the range of -0.3 to $0.5 \mathrm{~m} \mathrm{~s}^{-1}$. Meridional wind biases are below $0.1 \mathrm{~m} \mathrm{~s}^{-1}$ for all data sets. Standard deviations vary between 0.5 and $1.4 \mathrm{~K}$ for temperature, 0.9 and $2.3 \mathrm{~m} \mathrm{~s}^{-1}$ for the zonal wind, and 0.9 and $1.9 \mathrm{~m} \mathrm{~s}^{-1}$ for the meridional wind. Note that the largest biases and standard deviations were typically found for the NCEP/NCAR data set, which may be attributed to the fact that this data set is independent, whereas the Concordiasi balloon observations have been assimilated into the other analyses. However, the statistics show that there are still significant differences between the data sets with balloon data being assimilated (ECMWF products, MERRA, and MERRA-2), which shows that the analyses are also affected by other observations (e.g., satellite data) and the forecasts models and assimilation procedures.

Figure 5 shows large-scale state biases and standard deviations of temperatures and horizontal winds at different latitudes averaged over the entire time period of the campaign. Variations between different months are typically smaller (not shown). All analyses show an increasing temperature bias from mid to high latitudes. The temperature warm bias at $80-85^{\circ} \mathrm{S}$ is largest for NCEP/NCAR $(3.1 \mathrm{~K})$, followed by MERRA (1.4 K), MERRA-2 (1.3 K), ERA-Interim (1.1 K), and ECMWF OA $(0.5 \mathrm{~K})$. Note that temperature biases of meteorological analyses at the Southern Hemisphere winter pole were also reported for earlier winters in other studies (Gobiet et al., 2005; Parrondo et al., 2007; Boccara et al., 2008). Gobiet et al. (2005) speculate that the assimilation of microwave radiances from satellite measurements into ECMWF analyses may be a reason for the temperature bias. The magnitude of the temperature warm bias found here for NCEP/NCAR is comparable with those found in earlier studies. The temperature bias for the other analyses is smaller, which may be attributed to the fact the Concordiasi data have been assimilated. The same reason likely explains why wind biases as well as temperature and wind standard deviations shown in Fig. 5 are generally largest for NCEP/NCAR, whereas they are smaller and more similar to each other for both ECMWF data sets and MERRA-2.

Table 4 provides standard deviations of high-pass filtered horizontal winds for the analyses and the balloon data. Note that the balloon observations are an excellent source of data to study real small-scale fluctuations in the atmosphere, which are mostly attributed to gravity waves (e.g., Hertzog et al., 2008, 2012; Plougonven et al., 2013; Vincent and Hertzog, 2014; Jewtoukoff et al., 2015). A comparison of standard deviations allows us to assess how well small-scale fluctuations are represented in the meteorological analyses. We found that ECMWF OA reproduces about $60 \%$ and ERAInterim, MERRA, and MERRA- 2 about $30 \%$ of the standard deviations of the temperature and wind fluctuations of the balloons. NCEP/NCAR reproduces about $15 \%$ for temperature and $30 \%$ for the winds. These differences are associated with the spatial resolution of the analyses (see Table 2) because the forecast models are able to simulate gravity waves patterns more realistically if they are operating at higher spatial resolution. Our results are in excellent agreement with the studies of Jewtoukoff et al. (2015), which found that ECMWF analyses underestimate gravity wave momentum fluxes derived from the Concordiasi balloon observations by a factor of 5, and Hoffmann et al. (2017), which found that wave amplitudes in the ECMWF analyses are typically underestimated by a factor of 2-3 compared to Atmospheric InfraRed Sounder (AIRS/Aqua) observations. 
Table 3. Statistics of low-pass-filtered meteorological analyses minus Concordiasi balloon observations (based on $N \approx 2.52 \times 10^{6}$ measurements)

\begin{tabular}{lccccc}
\hline & ECMWF OA & ERA-Interim & MERRA-2 & MERRA & NCEP/NCAR \\
\hline Temperature (K) & & & & & \\
\hline Bias & 0.4 & 0.8 & 1.0 & 1.1 & 2.1 \\
Standard deviation & 0.5 & 0.6 & 0.7 & 0.9 & 1.4 \\
\hline Zonal wind ( $\mathrm{m} \mathrm{s}^{-1}$ ) & & & & & \\
Bias & 0.1 & 0.3 & 0.3 & 0.5 & -0.3 \\
Standard deviation & 0.9 & 1.0 & 1.1 & 1.6 & 2.3 \\
\hline Meridional wind (m s & & & & & \\
\hline Bias & & 0.1 & 0.0 & 0.1 & 0.1 \\
Standard deviation & 0.1 & 0.9 & 1.1 & 1.4 & 1.9 \\
\hline
\end{tabular}
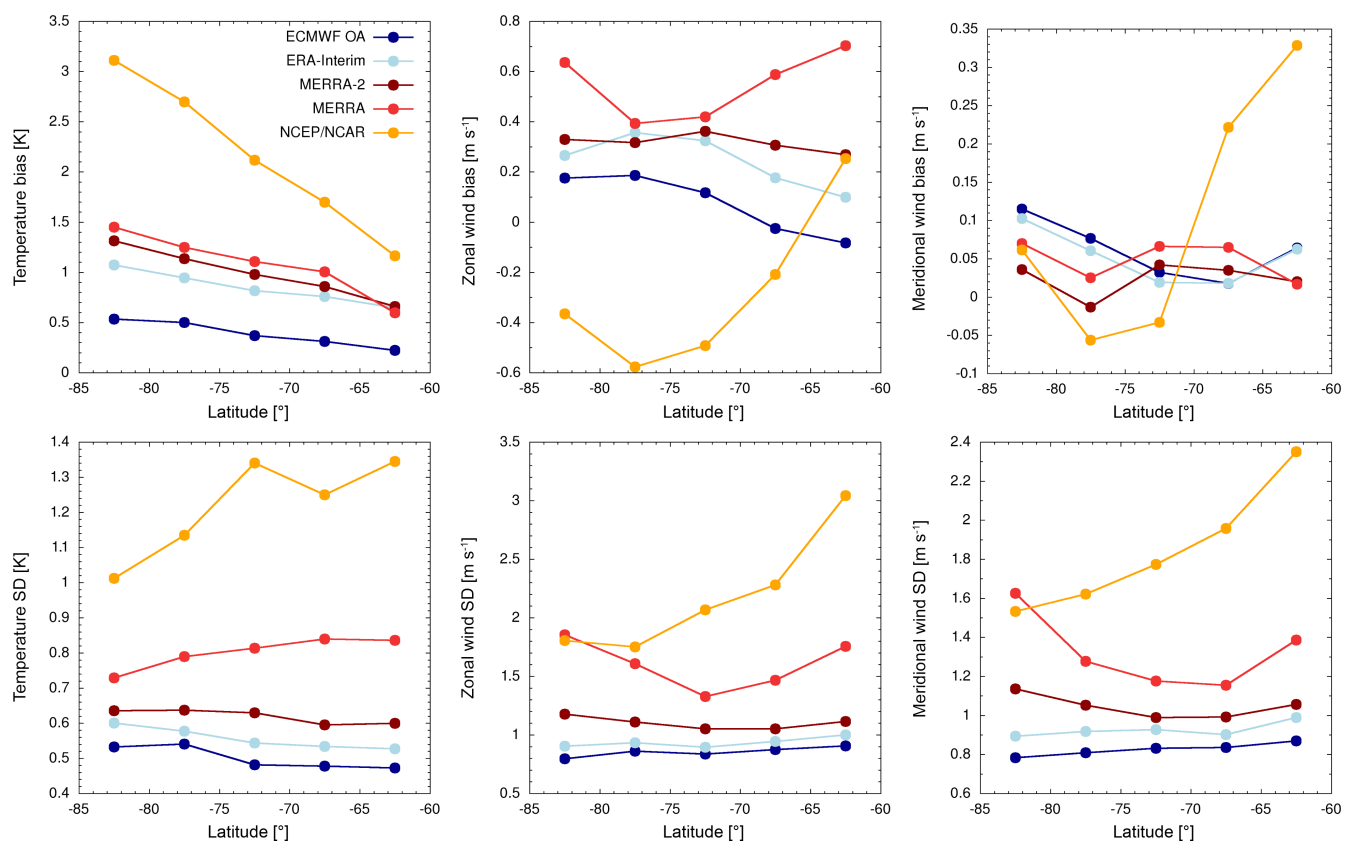

Figure 5. Bias and standard deviations of temperature and horizontal winds of meteorological analyses minus Concordiasi balloon data at different latitudes.

\subsection{Analysis of vertical motions}

In the remaining sections we focus on the evaluation of trajectory calculations using the MPTRAC model with Concordiasi superpressure balloon observations. As outlined in Sect. 2.3, we implemented several new options in the MPTRAC model to constrain the vertical motions of air parcels. We first tried to identify the approach that is best suited to simulate the vertical motions of the superpressure balloons in a realistic manner. Note that previous trajectory studies on tropospheric altitude-controlled balloons used pressure measurements to constrain vertical motions (Baumann and Stohl, 1997; Riddle et al., 2006). Trajectory evaluations with stratospheric superpressure balloons were con- ducted with the isopycnic approach (Hertzog et al., 2004; Boccara et al., 2008). In our comparison we considered vertical motions based on prescribed pressure time series as measured by the balloons, isopycnic motions, isentropic motions, and vertical motions prescribed by the vertical velocities of the meteorological data sets (referred to as "omega velocities" below).

For illustration, Fig. 6 shows examples of trajectories calculated with different types of vertical motions and the corresponding balloon observations. This comparison was conducted using ERA-Interim data as input for the trajectory calculations. Within 15 days the balloon is advected by the polar night jet over a distance of nearly $30000 \mathrm{~km}$ and encircles the South Pole more than twice. At the end of the sim- 
Table 4. Standard deviations of high-pass-filtered meteorological analyses and Concordiasi balloon observations.

\begin{tabular}{lrrrrrr}
\hline & Balloons & ECMWF OA & ERA-Interim & MERRA-2 & MERRA & NCEP/NCAR \\
\hline Temperature $(\mathrm{K})$ & 0.7 & 0.4 & 0.2 & 0.2 & 0.2 & 0.1 \\
Zonal wind $\left(\mathrm{m} \mathrm{s}^{-1}\right.$ ) & 1.5 & 0.9 & 0.4 & 0.4 & 0.4 & 0.4 \\
Meridional wind $\left(\mathrm{m} \mathrm{s}^{-1}\right.$ ) & 1.6 & 1.0 & 0.5 & 0.5 & 0.5 & 0.5 \\
\hline
\end{tabular}

CONCORDIASI (10V01N46) | 2010-09-23, 02:27 UTC

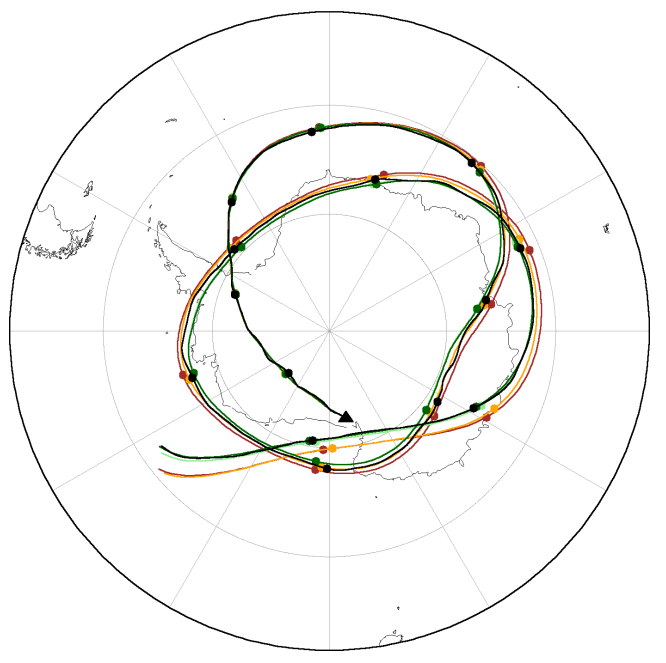

Figure 6. Comparison of 15-day trajectories calculated with different types of vertical motion (dark green: balloon pressure; light green: isopycnic; orange: isentropic; red: omega velocity) and corresponding Concordiasi balloon trajectory (black). The plot title provides the gondola ID and the starting time. The triangle indicates the starting position of the trajectories. Circles indicate trajectory positions at 00:00 UTC each day.

ulations we found horizontal transport deviations of about $30 \mathrm{~km}(0.1 \%)$ using the balloon pressure, $100 \mathrm{~km}(0.3 \%)$ for the isopycnic approach, $350 \mathrm{~km}(1.2 \%)$ for the isentropic approach, and $400 \mathrm{~km}(1.3 \%)$ for the omega velocity. In this particular example the balloon trajectory is reproduced with excellent accuracy by all simulations. We picked this particular example for presentation because the simulations are not strongly affected by any individual, complex meteorological conditions. In this example the balloon trajectory is best reproduced by constraining vertical movements based on the balloon pressure measurements or by using the isopycnic approach, as expected from the balloon dynamics (Sect. 2.1). Larger transport deviations are found using omega velocities and the isentropic approach. However, note that the trajectories based on omega velocities and the isentropic approach are in good agreement with each other, which was expected as atmospheric motions are isentropic on short timescales.

In order to take into account statistical variations, Fig. 7 shows transport deviations calculated from 104 samples of 15-day balloon trajectories of the Concordiasi campaign, which we selected according to the approach outlined in Sect. 2.4. The AHTDs increase rather steadily to about 1610$1750 \mathrm{~km}$ after 15 days. As in the example shown in Fig. 6, the results cluster in two groups. Trajectories calculated using the balloon pressure and the isopycnic approach are similar to each other and yield results at the lower end of the AHTD ranges. Trajectories calculated using omega velocities and the isentropic approach are also similar to each other and yield results at the upper end of the AHTD ranges. The corresponding RHTDs are in a range of 4-5\% after 2 days and increase to about $7 \%$ after 15 days. The mean difference between the two groups of simulations is about 0.7 percentage points. Note that RHTDs are quite large during the first $12-24 \mathrm{~h}$, which is not representative, because the calculations are based on rather short reference trajectories. In addition, Fig. 7 also shows vertical transport deviations based on the isopycnic and isentropic approach as well as omega velocities. The AVTDs of the isopycnic approach increase steadily to about $200 \mathrm{~m}$ after 15 days. The corresponding RVTDs converge at 6-7\% after 4 days. The AVTDs using omega velocities and the isentropic approach increase rapidly during the first 2 days and then increase more slowly up to 560$680 \mathrm{~m}$ after 15 days. The corresponding RVTDs converge to $17-21 \%$. A possible reason for larger initial deviations using omega velocities and the isentropic approach are uncertainties in the initial pressure values used to define the trajectory seeds. Simulations based on omega velocities or the isentropic approach are more strongly affected by short-term fluctuations of the initial pressure values than simulations based on the isopycnic approach. To mitigate uncertainties caused by short-term fluctuations, we used the mean pressure of the first $3 \mathrm{~h}$ of each balloon trajectory for initialization. However, our analysis still indicates that vertical motions are best calculated using either the balloon pressure measurements or the isopycnic approach. For the remaining analyses we decided to calculate the trajectories using the balloon pressure measurements because this takes into account changes in the overall mass configuration of the balloongondola system (Sect. 2.1).

\subsection{Impact of different meteorological analyses on trajectory calculations}

In this section we present a comparison of transport deviations obtained with different meteorological data sets. Figure 8 shows two examples of 15-day trajectory calculations 

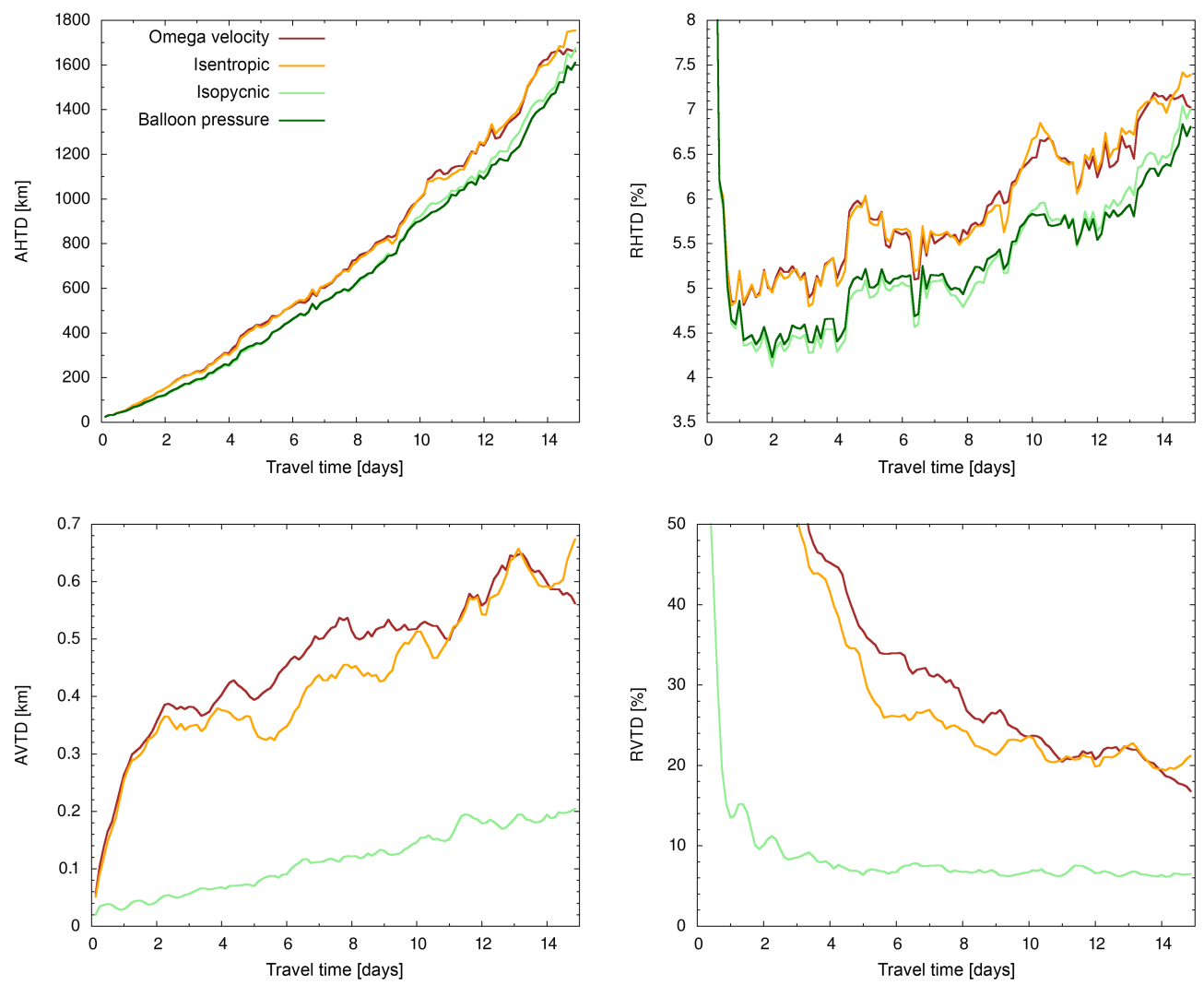

Figure 7. Transport deviations of simulated and observed balloon trajectories for different types of vertical motion. Trajectories were calculated with ERA-Interim horizontal winds. The analysis is based on 104 samples of 15-day trajectories from the Concordiasi campaign.

using ECMWF OA, ERA-Interim, MERRA, MERRA-2, and NCEP/NCAR data. The examples mainly serve to illustrate the large range of variability found in different simulations. For flight number 2 the simulated trajectories reproduce the observed balloon trajectory quite well. We found maximum AHTDs in a range of $650-1050 \mathrm{~km}$ and maximum RHTDs in a range of 3-7\% for the different data sets. Note that the maxima occur on different days - i.e., simulated trajectories may first deviate from and then approach the observed trajectories again. Despite being shorter (i.e., $12700 \mathrm{~km}$ versus $29700 \mathrm{~km}$ ), the simulated trajectories for flight number 12 deviate much more strongly from the observations. Here we found maximum AHTDs of $3100-5200 \mathrm{~km}$ and maximum RHTDs of 53-70\%. The two examples illustrate the large variability between different samples, which is attributed to situation-dependent factors such as the individual meteorological conditions. A large number of independent samples needs to be analyzed in order to obtain statistically significant results.

Figure 9 shows transport deviations for the different meteorological data sets calculated from 104 samples of 15-day trajectories (Sect. 2.4). In contrast to the individual examples, we found that the AHTDs increase rather steadily over time, which suggests that outliers play a minor role and that the statistics are robust. After 15 days the AHTDs are in a range of 1400 to $2200 \mathrm{~km}$. From Fig. 9 we can also estimate the growth rates of the AHTDs, which are typically within 60 to $170 \mathrm{~km} \mathrm{day}^{-1}$. The RHTDs are in a range of $4-12 \%$ after 2 days, but converge to a smaller range of 6-9\% after 15 days. Although the transport deviations grow rather steadily, the relative differences between the data sets tend to get smaller over time. The largest transport deviations and growth rates were found for NCEP/NCAR, which may be attributed to the fact that the wind data of this analysis are most uncertain because the Concordiasi balloon observation were not assimilated (Sect. 3.1). However, our results still agree well with those reported by Boccara et al. (2008) for the Vorcore campaign in 2005 , despite the fact that data assimilation of the balloon observations did not play a role in that study. For 15 days' trajectory time Boccara et al. (2008) found mean spherical distances of about $1650 \mathrm{~km}$ (with an interquartile range of $800-3600 \mathrm{~km}$ ) for ECMWF analyses and $2350 \mathrm{~km}$ $(1400-3800 \mathrm{~km})$ for NCEP/NCAR data. The transport deviations and growth rates found here also compare well with a wider range of results for the troposphere reported by Stohl (1998). 

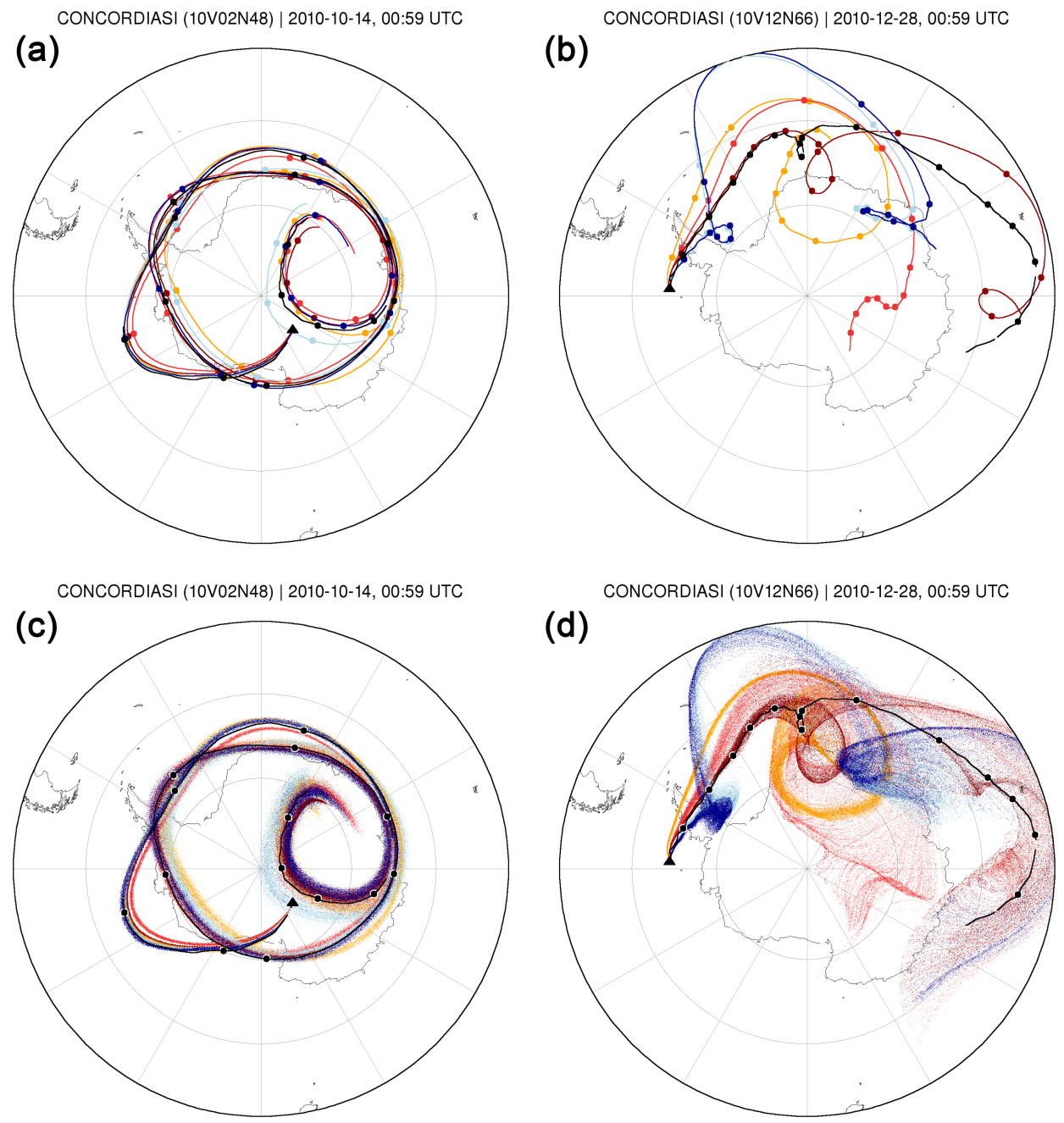

Figure 8. Examples of trajectories calculated with different meteorological analyses (dark blue: ECMWF OA; light blue: ERA-Interim; dark red: MERRA-2; light red: MERRA; orange: NCEP/NCAR) and corresponding Concordiasi balloon trajectory (black). Plot titles provide the starting times and triangles indicate the starting positions of the trajectories. Circles indicate trajectory positions at 00:00 UTC each day. Plots at the top show individual trajectories calculated without diffusion. Plots at the bottom illustrate dispersion simulations with diffusion being considered.

\subsection{Impact of subgrid-scale wind fluctuations}

In this section we discuss the influence of diffusion on the trajectory calculations. We assessed this by means of dispersion simulations, each consisting of 1000 trajectories for each sample, and by applying the MPTRAC diffusion module described in Sect. 2.3. Note that these simulations consider only horizontal diffusion, because vertical motions have been restricted to the pressure measurements of the balloons. Following Stohl et al. (2005), the turbulent horizontal diffusivity coefficient in the stratosphere was set to zero, $D_{x}=0$ - i.e., the diffusion in our simulations is related only to horizontal subgrid-scale wind fluctuations. For comparison with diffusion-free simulations, two examples of dispersion simulations are also shown in Fig. 8. For flight number 2 we found only minor spread of the air parcels due to diffusion, whereas for flight number 12 it is quite substantial, illustrating that diffusion may vary significantly from case to case. The examples also suggest that the uncertainties of the trajectory calculations are linked to the meteorological situation, as low diffusion goes along with good accuracy of the trajectories for flight number 2 , whereas high diffusion goes along with low accuracy for flight number 12 .

Kahl (1996) analyzed correlations between trajectory model errors and the complexity of the meteorological situation under study in more detail. He quantified the complexity of the meteorological conditions by means of the so-called "meteorological complexity factor" (MCF), which measures the dispersion of a set of stochastic trajectories generated by random perturbations superimposed upon an observed wind field. Kahl (1996) pointed out that trajectory errors are representative only if they are larger than the corresponding MCF. 

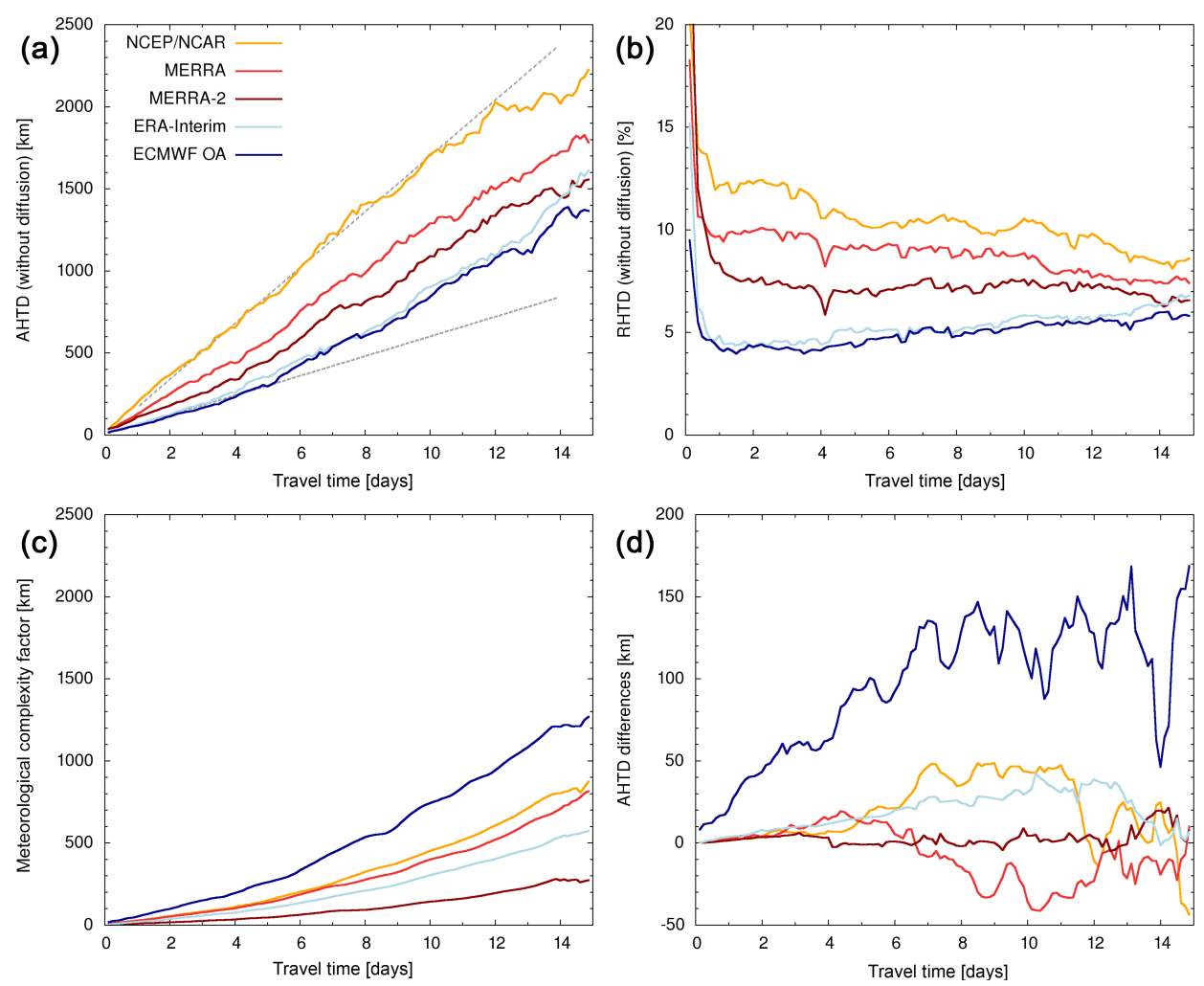

Figure 9. Horizontal transport deviations of simulated and observed balloon trajectories for different meteorological analyses (a, b). Dotted gray lines represent AHTD growth rates of 60 and $170 \mathrm{~km} \mathrm{day}^{-1}$. Also shown are the meteorological complexity factor for dispersion simulations (c) and the AHTD differences that are introduced by adding diffusion (d).

Similar to Kahl (1996), we estimated the MCF of our simulations by applying Eq. (4) to the trajectory ensemble. However, instead of taking the balloon trajectory as a reference, the MCF was calculated using a simulated trajectory without diffusion as a reference. The simulated reference trajectory is usually close to the ensemble mean because the deviations of the ensemble trajectories are often symmetric around the ensemble mean. The MCFs of the five meteorological data sets of our study are shown in Fig. 9. The MCFs increase rather steadily over time. After 15 days we found values of about $1300 \mathrm{~km}$ for ECMWF OA, $800-900 \mathrm{~km}$ for MERRA and NCEP/NCAR, $600 \mathrm{~km}$ for ERA-Interim, and $300 \mathrm{~km}$ for MERRA-2. These differences in the MCFs came somewhat unexpected, as the spread of air parcels ideally should be the same in all simulations, independent of the meteorological data set and the diffusion model being applied. The differences are not directly related to the resolution of the meteorological data sets, as can be seen from the ranking of the MCFs of the data sets. The inconsistencies of the MCFs found here might be due to dynamical inconsistencies of the analysis wind fields that are introduced during the data assimilation process. Such dynamical inconsistencies may lead to more rapid dispersion and spurious mixing in Lagrangian transport model simulations (Stohl et al., 2004).
In principle, we may tune the scaling factor $\alpha$ in Eq. (3) of the MPTRAC diffusion module to achieve simulations with more consistent MCFs. However, we refrained from any tuning measures, because appropriate reference data are lacking. We applied a constant scaling factor $\alpha=0.16$ in all simulations, which is the default value used in the FLEXPART model. However, despite the different levels of MCFs found in the simulations, we conclude that the transport deviations between the simulations and the balloons can be considered representative, because they are notably larger than the MCFs. To further confirm this result we also calculated the AHTDs between the trajectory ensembles and the balloon trajectories. We found that the transport deviations with or without diffusion are rather similar (Fig. 9). The AHTDs for ERA-Interim, MERRA, MERRA-2, and NCEP/NCAR differ less than $\pm 50 \mathrm{~km}$. For ECMWF OA the AHTDs with diffusion are up to $200 \mathrm{~km}$ larger than the AHTDs without diffusion. We attribute this to the fact that simulated diffusion is largest for ECMWF OA, as indicated by the corresponding MCFs. This shows that diffusion does not induce any significant uncertainties in our analysis of transport deviations. The results remain meaningful, even if diffusion is not explicitly taken into account. 


\section{Summary and conclusions}

In this study we conducted an intercomparison of temperatures and horizontal winds from the ECMWF operational analysis and the ERA-Interim, MERRA, MERRA-2, and NCEP/NCAR reanalyses at Southern Hemisphere mid- and high latitudes in the lower stratosphere. The analyses were compared with Concordiasi superpressure balloon observations in September 2010 to January 2011. Most of the balloon observations took place at $60-85^{\circ} \mathrm{S}$ latitude and $17-18.5 \mathrm{~km}$ altitude. In this comparison we had to consider that $15 \mathrm{~min}$ downsampled Concordiasi data have been assimilated into both ECMWF data sets, MERRA and MERRA-2, but that they were not considered for the NCEP/NCAR reanalysis. For the direct intercomparison of the temperature and wind data at the balloon positions, a band-pass filter with $15 \mathrm{~h}$ cutoff period was applied to separate between the large-scale state and small-scale features.

The most prominent finding regarding the large-scale state was a temperature warm bias of the analyses at high latitudes. This bias was largest for NCEP/NCAR (up to $3.1 \mathrm{~K}$ at $80-85^{\circ} \mathrm{S}$ ), but it was also present in the other analyses (up to $0.5-1.4 \mathrm{~K}$ at $80-85^{\circ} \mathrm{S}$ ), despite the fact that the balloon observations have been assimilated. Stratospheric temperature biases for the Southern Hemisphere polar vortex have already been found in other studies for earlier winters (Gobiet et al., 2005; Parrondo et al., 2007; Boccara et al., 2008). Our study indicates that they were still present in 2010/2011. Zonal and meridional wind biases of the low-pass-filtered data are below $\pm 0.5 \mathrm{~m} \mathrm{~s}^{-1}$. Standard deviations are in the range of 0.4 $1.4 \mathrm{~K}$ for temperature and $0.9-2.3 \mathrm{~m} \mathrm{~s}^{-1}$ for the horizontal wind components. We found significant differences between the meteorological analyses, even with the balloon data being assimilated, which suggests that the analyses are also significantly affected by other observations and the different forecast models and assimilation procedures. Observing system experiments would be required to assess the specific impact of the balloon observations on the analyses.

The five meteorological data sets considered in our study differ significantly in spatial and temporal resolution. The truncation of the models plays an important role in determining how well the analyses are capable of representing small-scale fluctuations. A number of studies already demonstrated that superpressure balloon observations are particularly suited to study gravity waves (e.g., Hertzog et al., 2008, 2012; Plougonven et al., 2013; Vincent and Hertzog, 2014; Jewtoukoff et al., 2015). Standard deviations of high-passfiltered temperature and wind data of the balloons are reproduced at a level of about $60 \%$ by the ECMWF operational analysis, but only at a level of $15-30 \%$ by the reanalyses. For ECMWF operational analysis temperatures this is consistent with recent studies of Jewtoukoff et al. (2015) and Hoffmann et al. (2017), providing further evidence that the ECMWF operational model explicitly resolves a significant portion of the atmospheric gravity wave spectrum.
We also used the Concordiasi balloon observations to evaluate trajectory calculations with our rather new Lagrangian particle dispersion model MPTRAC. Some difficulties are related to the fact that the overall mass configuration of the balloon-gondola system changed during some of the flights. The analysis of vertical motions confirmed that balloon trajectories are best reproduced by the isopycnic approach (Hertzog et al., 2004; Boccara et al., 2008) or by nudging vertical motions to the pressure measurements of the balloons (Baumann and Stohl, 1997; Riddle et al., 2006). In this study we analyzed 104 samples of trajectories from 19 balloon flights for time periods of 15 days. Absolute horizontal transport deviations typically grow at rates of 60 $170 \mathrm{~km} \mathrm{day}^{-1}$ for all data sets. Relative horizontal transport deviations showed larger differences at the beginning of the simulations, but converged to a range of 6-9\% after 15 days. The largest transport deviations and growth rates were found for NCEP/NCAR, which may be attributed to the fact that the Concordiasi balloon observation were not assimilated into this analysis. In general, our results compare well with those reported by Boccara et al. (2008) for the Vorcore campaign in 2005, despite the fact that data assimilation of the balloon observations did not play a role in that study.

In order to assess the impact of diffusion we conducted dispersion simulations with MPTRAC. The analysis revealed some difficulties with the modeling approach for subgridscale wind fluctuations and the wind data driving these simulations, as the spread of air parcel trajectories simulated with different meteorological data sets was not consistent. We also did not find correlations between the spread and the spatial and temporal resolution of the data sets. Future work may comprise additional analyses and focus on tuning of the subgrid-scale parametrization scheme. Selected examples of dispersion simulations indicate that the accuracy of trajectory calculations is linked to meteorological complexity, as suggested by Kahl (1996). In this study we analyzed a rather large number of trajectory samples, though, and the effects of meteorological complexity averaged out and did not alter the results of the analysis of transport deviations significantly. The evaluation suggests that the MPTRAC model is capable of calculating trajectories in the Antarctic lower stratosphere with an accuracy similar to that obtained in other studies. The methods and results should be transferable to other Lagrangian transport models for the stratosphere and may help to improve future studies using these models to assess the dynamics of the polar vortex or to investigate polar ozone loss.

Code and data availability. The quality-controlled meteorological TSEN data set is available from Laboratoire de Météorologie Dynamique (LMD) from their web site at http://www.lmd. polytechnique.fr/VORCORE/McMurdoE.htm (Rabier et al., 2010). The ERA-Interim reanalysis and operational analyses are distributed by the European Centre for Medium-Range Weather Fore- 
casts (ECMWF); see http://www.ecmwf.int/en/forecasts/datasets (Dee et al., 2011). MERRA data (Rienecker et al., 2011) and MERRA-2 data (Bosilovich et al., 2015) are provided by the Global Modeling and Assimilation Office at NASA Goddard Space Flight Center through the NASA GES DISC online archive; see https: //disc.gsfc.nasa.gov/mdisc/overview. NCEP/NCAR reanalysis data were obtained from the NOAA/OAR/ESRL PSD, Boulder, Colorado, USA, from their web site at http://www.esrl.noaa.gov/psd (Kalnay et al., 1996). The code of the Massive-Parallel Trajectory Calculations (MPTRAC) model is available under the terms and conditions of the GNU General Public License, Version 3, from the repository at https://github.com/slcs-jsc/mptrac (last access: 21 December 2016).

Author contributions. All authors contributed to the design of the study and provided input to the manuscript. LH conducted the transport simulations and the scientific analysis. $\mathrm{AH}$ provided support regarding the scientific analysis of the Concordiasi superpressure balloon observations. TR and OS were responsible for preprocessing of the meteorological data. XW provided the characterization of the meteorological conditions during the campaign.

Competing interests. The authors declare that they have no conflict of interest.

Acknowledgements. Concordiasi was built by an international scientific group and is currently supported by the following agencies: Météo-France, CNES, IPEV, PNRA, CNRS/INSU, NSF, NCAR, the Concordia consortium, the University of Wyoming, and Purdue University. ECMWF also contributes to the project through computer resources and support, as well as scientific expertise. The two operational polar agencies PNRA and IPEV are thanked for their support at Concordia station. Concordiasi is part of the THORPEX-IPY cluster within the International Polar Year effort. The authors acknowledge the Jülich Supercomputing Centre (JSC) for providing computing time on the supercomputer JURECA.

The article processing charges for this open-access

publication were covered by a Research

Centre of the Helmholtz Association.

Edited by: Farahnaz Khosrawi

Reviewed by: Andreas Stohl and two anonymous referees

\section{References}

Baldwin, M. P. and Dunkerton, T. J.: Propagation of the Arctic Oscillation from the stratosphere to the troposphere, J. Geophys. Res., 104, 30937-30946, 1999.

Baldwin, M. P., Thompson, D. W., Shuckburgh, E. F., Norton, W. A., and Gillett, N. P.: Weather from the stratosphere?, Science, 301, 317-319, 2003.

Baumann, K. and Stohl, A.: Validation of a Long-Range Trajectory Model Using Gas Balloon Tracks from the Gordon Bennett Cup
95, J. Appl. Met., 36, 711-720, https://doi.org/10.1175/15200450-36.6.711, 1997.

Boccara, G., Hertzog, A., Basdevant, C., and Vial, F.: Accuracy of NCEP/NCAR reanalyses and ECMWF analyses in the lower stratosphere over Antarctica in 2005, J. Geophys. Res., 113, D20115, https://doi.org/10.1029/2008JD010116, 2008.

Bosilovich, M., Akella, S., Coy, L., Cullather, R., Draper, C., Gelaro, R., Kovach, R., Liu, Q., Molod, A., Norris, P., Wargan, K., Chao, W., Reichle, R., Takacs, L., Vikhliaev, Y., Bloom, S., Collow, A., Firth, S., Labow, G., Partyka, G., Pawson, S., Reale, O., Schubert, S. D., and Suarez, M.: MERRA-2: Initial evaluation of the climate, Tech. rep., NASA, series on Global Modeling and Data Assimilation, NASA/TM-2015-104606, Vol. 43, 2015.

Bowman, K. P., Lin, J. C., Stohl, A., Draxler, R., Konopka, P., Andrews, A., and Brunner, D.: Input Data Requirements for Lagrangian Trajectory Models, B. Am. Meteorol. Soc., 94, 10511058, 2013.

Chipperfield, M. P.: Multiannual Simulations with a ThreeDimensional Chemical Transport Model, J. Geophys. Res., 104, 1781-1805, 1999.

De Laat, A. and van Weele, M.: The 2010 Antarctic ozone hole: Observed reduction in ozone destruction by minor sudden stratospheric warmings, Sci. Rep., 1, 38, https://doi.org/10.1038/srep00038, 2011.

Dee, D. P., Uppala, S. M., Simmons, A. J., Berrisford, P., Poli, P., Kobayashi, S., Andrae, U., Balmaseda, M. A., Balsamo, G., Bauer, P., Bechtold, P., Beljaars, A. C. M., van de Berg, L., Bidlot, J., Bormann, N., Delsol, C., Dragani, R., Fuentes, M., Geer, A. J., Haimberger, L., Healy, S. B., Hersbach, H., Hólm, E. V., Isaksen, L., Kãllberg, P., Köhler, M., Matricardi, M., McNally, A. P., Monge-Sanz, B. M., Morcrette, J.-J., Park, B.-K., Peubey, C., de Rosnay, P., Tavolato, C., Thépaut, J.-N., and Vitart, F.: The ERA-Interim reanalysis: configuration and performance of the data assimilation system, Q. J. Roy. Meteor. Soc., 137, 553-597, https://doi.org/10.1002/qj.828, 2011 (data available at: http://www.ecmwf.int/en/forecasts/datasets, last access: 21 December 2016).

Friedrich, L. S., McDonald, A. J., Bodeker, G. E., Cooper, K. E., Lewis, J., and Paterson, A. J.: A comparison of Loon balloon observations and stratospheric reanalysis products, Atmos. Chem. Phys., 17, 855-866, https://doi.org/10.5194/acp-17-8552017, 2017.

Fujiwara, M., Wright, J. S., Manney, G. L., Gray, L. J., Anstey, J., Birner, T., Davis, S., Gerber, E. P., Harvey, V. L., Hegglin, M. I., Homeyer, C. R., Knox, J. A., Krüger, K., Lambert, A., Long, C. S., Martineau, P., Molod, A., Monge-Sanz, B. M., Santee, M. L., Tegtmeier, S., Chabrillat, S., Tan, D. G. H., Jackson, D. R., Polavarapu, S., Compo, G. P., Dragani, R., Ebisuzaki, W., Harada, Y., Kobayashi, C., McCarty, W., Onogi, K., Pawson, S., Simmons, A., Wargan, K., Whitaker, J. S., and Zou, C.-Z.: Introduction to the SPARC Reanalysis Intercomparison Project (S-RIP) and overview of the reanalysis systems, Atmos. Chem. Phys., 17, 1417-1452, https://doi.org/10.5194/acp17-1417-2017, 2017.

Gobiet, A., Foelsche, U., Steiner, A. K., Borsche, M., Kirchengast, G., and Wickert, J.: Climatological validation of stratospheric temperatures in ECMWF operational analyses with CHAMP radio occultation data, Geophys. Res. Lett., 32, L12806, https://doi.org/10.1029/2005GL022617, 2005. 
Grooß, J.-U., Günther, G., Konopka, P., Müller, R., McKenna, D. S., Stroh, F., Vogel, B., Engel, A., Müller, M., Hoppel, K., Bevilacqua, R., Richard, E., Webster, C. R., Elkins, J. W., Hurst, D. F., Romashkin, P. A., and Baumgardner, D. G.: Simulation of ozone depletion in spring 2000 with the Chemical Lagrangian Model of the Stratosphere (CLaMS), J. Geophys. Res., 107, 8295, https://doi.org/10.1029/2001JD000456, 2002.

Grooß, J.-U., Konopka, P., and Müller, R.: Ozone Chemistry during the 2002 Antarctic Vortex Split, J. Atmos. Sci., 62, 860-870, 2005

Heng, Y., Hoffmann, L., Griessbach, S., Rößler, T., and Stein, O.: Inverse transport modeling of volcanic sulfur dioxide emissions using large-scale simulations, Geosci. Model Dev., 9, 16271645, https://doi.org/10.5194/gmd-9-1627-2016, 2016.

Hertzog, A., Basdevant, C., Vial, F., and Mechoso, C.: The accuracy of stratospheric analyses in the northern hemisphere inferred from long-duration balloon flights, Q. J. Roy. Meteor. Soc., 130, 607-626, 2004.

Hertzog, A., Basdevant, C., and Vial, F.: An Assessment of ECMWF and NCEP-NCAR Reanalyses in the Southern Hemisphere at the End of the Presatellite Era: Results from the EOLE Experiment (1971-72), Mon. Weather Rev., 134, 3367-3383, 2006

Hertzog, A., Boccara, G., Vincent, R. A., Vial, F., and Cocquerez, P.: Estimation of gravity wave momentum flux and phase speeds from quasi-Lagrangian stratospheric balloon flights. Part II: Results from the Vorcore campaign in Antarctica, J. Atmos. Sci., 65, 3056-3070, 2008.

Hertzog, A., Alexander, M. J., and Plougonven, R.: On the intermittency of gravity wave momentum flux in the stratosphere, J. Atmos. Sci., 69, 3433-3448, 2012.

Hoffmann, L., Rößler, T., Griessbach, S., Heng, Y., and Stein, O.: Lagrangian transport simulations of volcanic sulfur dioxide emissions: impact of meteorological data products, J. Geophys. Res., 121, 4651-4673, https://doi.org/10.1002/2015JD023749, 2016.

Hoffmann, L., Spang, R., Orr, A., Alexander, M. J., Holt, L. A., and Stein, O.: A decadal satellite record of gravity wave activity in the lower stratosphere to study polar stratospheric cloud formation, Atmos. Chem. Phys., 17, 2901-2920, https://doi.org/10.5194/acp-17-2901-2017, 2017.

Jewtoukoff, V., Hertzog, A., Plougonven, R., Cámara, A. d. 1., and Lott, F.: Comparison of Gravity Waves in the Southern Hemisphere Derived from Balloon Observations and the ECMWF Analyses, J. Atmos. Sci., 72, 3449-3468, 2015.

Kahl, J. D.: On the prediction of trajectory model error, Atmos. Environ., 30, 2945-2957, 1996.

Kalnay, E., Kanamitsu, M., Kistler, R., Collins, W., Deaven, D., Gandin, L., Iredell, M., Saha, S., White, G., Woollen, J., Zhu, Y., Chelliah, M., Ebisuzaki, W., Higgins, W., Janowiak, J., Mo, K. C., Ropelewski, C., Wang, J., Leetmaa, A., Reynolds, R., Jenne, R., and Joseph, D.: The NCEP/NCAR 40-year reanalysis project, B. Am. Meteorol. Soc., 77, 437-471, https://doi.org/10.1175/15200477(1996)077<0437:TNYRP>2.0.CO;2, 1996 (data available at: http://www.esrl.noaa.gov/psd, last access: 21 December 2016).

Klekociuk, A., Tully, M., Alexander, S., Dargaville, R., Deschamps, L., Fraser, P., Gies, H., Henderson, S., Javorniczky, J., Krummel,
P., Petelina, S., Shanklin, J., Siddaway, J., and Stone, K.: The Antarctic ozone hole during 2010, Aust. Meteor. Ocean. J., 61, 253-267, 2011.

Knudsen, B., Rosen, J., Kjome, N., and Whitten, A.: Comparison of analyzed stratospheric temperatures and calculated trajectories with long-duration balloon data, J. Geophys. Res., 101, 1913719145, 1996.

Knudsen, B. M., Pommereau, J.-P., Garnier, A., Nunes-Pinharanda, M., Denis, L., Newman, P., Letrenne, G., and Durand, M.: Accuracy of analyzed stratospheric temperatures in the winter Arctic vortex from infrared Montgolfier long-duration balloon flights 2. Results, J. Geophys. Res.-Atmos., 107, SOL 4-1-SOL 4-13, https://doi.org/10.1029/2001JD001329, 2002.

Knudsen, B. M., Christensen, T., Hertzog, A., Deme, A., Vial, F., and Pommereau, J.-P.: Accuracy of analyzed temperatures, winds and trajectories in the Southern Hemisphere tropical and midlatitude stratosphere as compared to long-duration balloon flights, Atmos. Chem. Phys., 6, 5391-5397, https://doi.org/10.5194/acp6-5391-2006, 2006.

Kuo, Y.-H., Skumanich, M., Haagenson, P. L., and Chang, J. S.: The accuracy of trajectory models as revealed by the observing system simulation experiments, Mon. Weather Rev., 113, 18521867, 1985.

Lawrence, Z. D., Manney, G. L., Minschwaner, K., Santee, M. L., and Lambert, A.: Comparisons of polar processing diagnostics from 34 years of the ERA-Interim and MERRA reanalyses, Atmos. Chem. Phys., 15, 3873-3892, https://doi.org/10.5194/acp15-3873-2015, 2015.

Legras, B., Joseph, B., and Lefèvre, F.: Vertical diffusivity in the lower stratosphere from Lagrangian back-trajectory reconstructions of ozone profiles, J. Geophys. Res., 108, 4562, https://doi.org/10.1029/2002JD003045, 2003.

Lin, J., Brunner, D., Gerbig, C., Stohl, A., Luhar, A., and Webley, P., eds.: Lagrangian modeling of the atmosphere, vol. 200 of Geophysical Monograph Series, American Geophysical Union, Washington DC, 2012.

Manney, G. L., Swinbank, R., Massie, S. T., Gelman, M. E., Miller, A. J., Nagatani, R., O'Neill, A., and Zurek, R. W.: Comparison of U.K. Meteorological Office and U.S. National Meteorological Center stratospheric analyses during northern and southern winter, J. Geophys. Res., 101, 10311-10334, https://doi.org/10.1029/95JD03350, 1996.

Manney, G. L., Allen, D. R., Krüger, K., Naujokat, B., Santee, M. L., Sabutis, J. L., Pawson, S., Swinbank, R., Randall, C. E., Simmons, A. J., et al.: Diagnostic comparison of meteorological analyses during the 2002 Antarctic winter, Mon. Weather Rev., 133, 1261-1278, 2005.

Maryon, R.: Determining cross-wind variance for low frequency wind meander, Atmos. Environ., 32, 115-121, 1998.

McKenna, D. S., Grooß, J.-U., Günther, G., Konopka, P., Müller, R., Carver, G., and Sasano, Y.: A new Chemical Lagrangian Model of the Stratosphere (CLaMS) 2. Formulation of chemistry scheme and initialization, J. Geophys. Res., 107, ACH 4-1-ACH 4-14, https://doi.org/10.1029/2000JD000113, 2002a.

McKenna, D. S., Konopka, P., Grooß, J.-U., Günther, G., Müller, R., Spang, R., Offermann, D., and Orsolini, Y.: A new Chemical Lagrangian Model of the Stratosphere (CLaMS) 1. Formulation of advection and mixing, J. Geophys. Res., 107, ACH 15-1-ACH 15-15, https://doi.org/10.1029/2000JD000114, 2002b. 
Newman, P. A. and Schoeberl, M. R.: Middle atmosphere: Polar vortex, in: Encyclopedia of Atmospheric Sciences, edited by: Holton, J. R., Pyle, J., and Curry, J. A., 1321-1328, Academic, San Diego, Calif., 2003.

Parrondo, M. C., Yela, M., Gil, M., von der Gathen, P., and Ochoa, H.: Mid-winter lower stratosphere temperatures in the Antarctic vortex: comparison between observations and ECMWF and NCEP operational models, Atmos. Chem. Phys., 7, 435-441, https://doi.org/10.5194/acp-7-435-2007, 2007.

Plougonven, R., Hertzog, A., and Guez, L.: Gravity waves over Antarctica and the Southern Ocean: Consistent momentum fluxes in mesoscale simulations and stratospheric balloon observations, Q. J. Roy. Meteor. Soc., 139, 101-118, 2013.

Podglajen, A., Hertzog, A., Plougonven, R., and Žagar, N.: Assessment of the accuracy of (re)analyses in the equatorial lower stratosphere, J. Geophys. Res., 119, 11166-11188, 2014.

Polvani, L. M. and Kushner, P. J.: Tropospheric response to stratospheric perturbations in a relatively simple general circulation model, Geophys. Res. Lett., 29, 1114, https://doi.org/10.1029/2001GL014284, 2002.

Rabier, F., Bouchard, A., Brun, E., Doerenbecher, A., Guedj, S., Guidard, V., Karbou, F., Peuch, V.-H., El Amraoui, L., Puech, D., et al.: The CONCORDIASI project in Antarctica, B. Am. Meteorol. Soc., 91, 69-86, https://doi.org/10.1175/2009BAMS2764.1, 2010 (data available at: http://www.lmd.polytechnique.fr/ VORCORE/McMurdoE.htm, last access: 21 December 2016).

Rabier, F., Cohn, S., Cocquerez, P., Hertzog, A., Avallone, L., Deshler, T., Haase, J., Hock, T., Doerenbecher, A., Wang, J., Guidard, V., Thépaut, J.-N., Langland, R., Tangborn, A., Balsamo, G., Brun, E., Parsons, D., Bordereau, J., Cardinali, C., Danis, F., Escarnot, J.-P., Fourrié, N., Gelaro, R., Genthon, C., Ide, K., Kalnajs, L., Martin, C., Meunier, L.-F., Nicot, J.-M., Perttula, T., Potts, N., Ragazzo, P., Richardson, D., Sosa-Sesma, S., and Vargas, A.: The Concordiasi Field Experiment over Antarctica: First Results from Innovative Atmospheric Measurements, B. Am. Meteorol. Soc., 94, ES17-ES20, https://doi.org/10.1175/BAMSD-12-00005.1, 2013.

Rex, M., Harris, N., Von der Gathen, P., Lehmann, R., Braathen, G., Reimer, E., Beck, A., Chipperfield, M., Alfier, R., Allaart, M., O'Connor, F., Dier, H., Dorokhov, V., Fast, H., Gil, M., Kyrö, E., Litynska, Z., Mikkelsen, I., Molyneux, M., Nakane, H., Notholt, J., Rummukainen, M., Viatte, P., and Wenger, J.: Prolonged stratospheric ozone loss in the 1995-96 arctic winter, Nature, 389, 835-838, 1997.

Riddle, E. E., Voss, P. B., Stohl, A., Holcomb, D., Maczka, D., Washburn, K., and Talbot, R. W.: Trajectory model validation using newly developed altitude-controlled balloons during the International Consortium for Atmospheric Research on Transport and Transformations 2004 campaign, J. Geophys. Res., 111, D23S57, https://doi.org/10.1029/2006JD007456, 2006.

Rienecker, M. M., Suarez, M. J., Gelaro, R., Todling, R., Bacmeister, J., Liu, E., Bosilovich, M. G., Schubert, S. D., Takacs, L., Kim, G.-K., Bloom, S., Chen, J., Collins, D., Conaty, A., da Silva, A., Gu, W., Joiner, J., Koster, R. D., Lucchesi, R., Molod, A., Owens, T., Pawson, S., Pegion, P., Redder, C. R., Reichle, R., Robertson, F. R., Ruddick, A. G., Sienkiewicz, M., and Woollen, J.: MERRA: NASA's Modern-Era Retrospective Analysis for Research and Applications, J. Climate, 24, 36243648, https://doi.org/10.1175/JCLI-D-11-00015.1, 2011 (data available at: https://disc.gsfc.nasa.gov/mdisc/overview, last access: 29 June 2017).

Rolph, G. D. and Draxler, R. R.: Sensitivity of three-dimensional trajectories to the spatial and temporal densities of the wind field, J. Appl. Met., 29, 1043-1054, 1990.

Rößler, T., Stein, O., Heng, Y., and Hoffmann, L.: Regional and seasonal truncation errors of trajectory calculations using ECMWF high-resolution operational analyses and forecasts, Geosci. Model Dev. Discuss., https://doi.org/10.5194/gmd-2016314, in review, 2017.

Schoeberl, M. R. and Hartmann, D. L.: The Dynamics of the Stratospheric Polar Vortex and Its Relation to Springtime Ozone Depletions, Science, 251, 46-52, 1991.

Schulzweida, U.: CDO User's Guide, Max-Planck-Institut für Meteorologie, Hamburg, available at: https://code.zmaw.de/projects/ cdo (last access: 27 May 2015), 2014.

Solomon, S.: Stratospheric ozone depletion: A review of concepts and history, Rev. Geophys., 37, 275-316, 1999.

Stohl, A.: Computation, accuracy and applications of trajectories a review and bibliography, Atmos. Environ., 32, 947-966, 1998.

Stohl, A., Wotawa, G., Seibert, P., and Kromp-Kolb, H.: Interpolation errors in wind fields as a function of spatial and temporal resolution and their impact on different types of kinematic trajectories, J. Appl. Met., 34, 2149-2165, 1995.

Stohl, A., Cooper, O., and James, P.: A cautionary note on the use of meteorological analysis fields for quantifying atmospheric mixing, J. Atmos. Sci., 61, 1446-1453, 2004.

Stohl, A., Forster, C., Frank, A., Seibert, P., and Wotawa, G.: Technical note: The Lagrangian particle dispersion model FLEXPART version 6.2, Atmos. Chem. Phys., 5, 2461-2474, https://doi.org/10.5194/acp-5-2461-2005, 2005.

Thompson, D. W. J., Baldwin, M. P., and Wallace, J. M.: Stratospheric Connection to Northern Hemisphere Wintertime Weather: Implications for Prediction, J. Climate, 15, 1421-1428, 2002.

Vincent, R. A. and Hertzog, A.: The response of superpressure balloons to gravity wave motions, Atmos. Meas. Tech., 7, $1043-$ 1055, https://doi.org/10.5194/amt-7-1043-2014, 2014

von der Gathen, P., Rex, M., Harris, N. R. P., Lucic, D., Knudsen, B. M., Braathen, G. O., De Backer, H., Fabian, R., Fast, H., Gil, M., Kyro, E., Mikkelsen, I. S., Rummukainen, M., Stahelin, J., and Varotsos, C.: Observational evidence for chemical ozone depletion over the Arctic in winter 1991-92, Nature, 375, 131-134, 1995.

Waugh, D. W. and Polvani, L. M.: Stratospheric polar vortices, The Stratosphere: Dynamics, Transport, and Chemistry, Geophys. Monogr. Ser, 190, 43-57, 2010.

Wohltmann, I. and Rex, M.: The Lagrangian chemistry and transport model ATLAS: validation of advective transport and mixing, Geosci. Model Dev., 2, 153-173, https://doi.org/10.5194/gmd-2153-2009, 2009.

Wohltmann, I., Wegner, T., Müller, R., Lehmann, R., Rex, M., Manney, G. L., Santee, M. L., Bernath, P., Suminska-Ebersoldt, O., Stroh, F., von Hobe, M., Volk, C. M., Hösen, E., Ravegnani, F., Ulanovsky, A., and Yushkov, V.: Uncertainties in modelling heterogeneous chemistry and Arctic ozone depletion in the winter 2009/2010, Atmos. Chem. Phys., 13, 3909-3929, https://doi.org/10.5194/acp-13-3909-2013, 2013. 